\title{
Acoustic monitoring indicates a correlation between calling and spawning in captive spotted seatrout (Cynoscion nebulosus)
}

\author{
Eric W Montie Corresp., 1 , Matt Hoover ${ }^{2}$, Christopher Kehrer ${ }^{1}$, Justin Yost ${ }^{3}$, Karl Brenkert ${ }^{3}$, Tim O'Donnell ${ }^{3}$, \\ Michael R Denson ${ }^{3}$ \\ 1 Department of Natural Sciences, University of South Carolina Beaufort, Bluffton, South Carolina, United States \\ 2 Department of Computational Science and Mathematics, University of South Carolina Beaufort, Bluffton, South Carolina, United States \\ 3 South Carolina Department of Natural Resources, Marine Resources Research Institute, Charleston, South Carolina, United States \\ Corresponding Author: Eric W Montie \\ Email address: emontie@uscb.edu
}

Background: Fish sound production is widespread throughout many families. Territorial displays and courtship are the most common reasons for fish sound production. Yet, there is still some questions on how acoustic signaling and reproduction are correlated in many sound-producing species. In the present study, our aim was to determine if a quantitative relationship exists between calling and egg deposition in captive spotted seatrout (Cynoscion nebulosus). This type of data is essential if passive acoustics is to be used to identify spawning aggregations over large spatial scales and monitor reproductive activity over annual and decadal timeframes. Methods: Acoustic recorders (i.e., DSG-Oceans) were placed in three laboratory tanks to record underwater sound over an entire, simulated reproductive season. We enumerated the number of calls, calculated the received sound pressure level, and counted the number of eggs every morning in each tank. Results: Spotted seatrout produced three distinct call types characterized as "drums", "grunts", and "staccatos". Spotted seatrout calling increased as the light cycle shifted from 13.5 to $14.5 \mathrm{~h}$ of light, and the temperature increased to $27.7^{\circ} \mathrm{C}$. Calling decreased once the temperature fell below $27.7^{\circ} \mathrm{C}$, and the light cycle shifted to $12 \mathrm{~h}$ of light. These temperature and light patterns followed the natural reproductive season observed in wild spotted seatrout in the Southeast United States. Spotted seatrout exhibited daily rhythms in calling. Acoustic signaling began once the lights turned off, and calling reached maximum activity approximately $3 \mathrm{~h}$ later. Eggs were released only on evenings in which spotted seatrout were calling. In all tanks, spotted seatrout were more likely to spawn when male fish called more frequently. A positive relationship between SPL and the number of eggs collected was found in Tanks 1 and 3. Discussion: Our findings indicate that acoustic metrics can predict spawning potential. These findings are important because plankton tows may not accurately reflect spawning locations since egg capture is 
likely affected by predator activity and water currents. Instead, passive acoustics could be used to monitor spotted seatrout reproduction. Future studies can use this captive study as a model to record the estuarine soundscape precisely over long time periods to better understand how human-made stressors (e.g., climate change, noise pollution, and chemical pollutants) may affect spawning patterns. 
1 Acoustic Monitoring Indicates a Correlation between Calling and Spawning in Captive

\section{Spotted Seatrout (Cynoscion nebulosus)}

3

4 Eric W. Montie ${ }^{1 *}$, Matt Hoover ${ }^{2}$, Chris Kehrer $^{1}$, Justin Yost ${ }^{3}, K_{\text {arl Brenkert }}{ }^{3}$, Tim O’Donnell ${ }^{3}$, 5 and Mike R. Denson ${ }^{3}$

6

$7{ }^{1}$ Department of Natural Sciences, University of South Carolina Beaufort, One University

8 Boulevard, Bluffton, South Carolina 29909, USA

9

${ }^{2}$ Department of Computational Science and Mathematics, University of South Carolina Beaufort,

One University Boulevard, Bluffton, South Carolina 29909, USA

${ }^{3}$ Marine Resources Research Institute, South Carolina Department of Natural Resources, P.O.

Box 12559, Charleston, South Carolina 29422, USA

Name and address of corresponding author:

*Eric W. Montie, Department of Natural Sciences, University of South Carolina Beaufort, One

University Boulevard, Bluffton, SC 29909; tel 843-208-8107; emontie@uscb.edu 


\section{ABSTRACT}

25 Background: Fish sound production is widespread throughout many families. Territorial displays and courtship are the most common reasons for fish sound production. Yet, there is still some questions on how acoustic signaling and reproduction are correlated in many soundproducing species. In the present study, our aim was to determine if a quantitative relationship exists between calling and egg deposition in captive spotted seatrout (Cynoscion nebulosus). This type of data is essential if passive acoustics is to be used to identify spawning aggregations over large spatial scales and monitor reproductive activity over annual and decadal timeframes.

Methods: Acoustic recorders (i.e., DSG-Oceans) were placed in three laboratory tanks to record underwater sound over an entire, simulated reproductive season. We enumerated the number of calls, calculated the received sound pressure level, and counted the number of eggs every morning in each tank.

Results: Spotted seatrout produced three distinct call types characterized as "drums", "grunts", and "staccatos". Spotted seatrout calling increased as the light cycle shifted from 13.5 to $14.5 \mathrm{~h}$ of light, and the temperature increased to $27.7^{\circ} \mathrm{C}$. Calling decreased once the temperature fell below $27.7^{\circ} \mathrm{C}$, and the light cycle shifted to $12 \mathrm{~h}$ of light. These temperature and light patterns followed the natural reproductive season observed in wild spotted seatrout in the Southeast United States. Spotted seatrout exhibited daily rhythms in calling. Acoustic signaling began once the lights turned off, and calling reached maximum activity approximately $3 \mathrm{~h}$ later. Eggs were released only on evenings in which spotted seatrout were calling. In all tanks, spotted seatrout were more likely to spawn when male fish called more frequently. A positive relationship between SPL and the number of eggs collected was found in Tanks 1 and 3. 
46 Discussion: Our findings indicate that acoustic metrics can predict spawning potential. These

47 findings are important because plankton tows may not accurately reflect spawning locations

48 since egg capture is likely affected by predator activity and water currents. Instead, passive

49 acoustics could be used to monitor spotted seatrout reproduction. Future studies can use this

50 captive study as a model to record the estuarine soundscape precisely over long time periods to

51 better understand how human-made stressors (e.g., climate change, noise pollution, and chemical

52 pollutants) may affect spawning patterns.

53

54

55

56

57

58

59

60

61

62

63

64

65

66

67

68 


\section{INTRODUCTION}

Many fish families contain species that produce sounds for communication purposes.

Some examples include African freshwater fishes (Mormyridae), damselfishes (Pomacentridae), grouper (Serranidae), catfishes (Ictaluridae, Pimelodidae, Doradidae, and Mochokidae), rockfishes (Sebastidae), haddock and cod (Gadidae), triglids (Triglidae), cichlids (Cichlidae), toadfishes (Batrachoididae), and drums (Sciaenidae) (e.g., Tavolga, 1958; Fish and Mowbray, 1970; Holt et al., 1985; Fine et al., 1990; Mann and Lobel, 1995; Amorim, 2006; Rowe and Hutchings, 2006; Luczkovich et al., 2008; Mann and Grothues, 2009; Parmentier et al., 2009; Walters et al., 2009; Širović et al., 2009; Mann et al., 2010; Locascio and Mann, 2011). One of the primary functions of sound production in fishes is for courtship during the reproductive season.

The Family Sciaenidae contains fish renowned for producing sound. Some representative examples include the Atlantic croaker (Micropogonias undulatus), red drum (Sciaenops ocellatus), weakfish (Cynoscion regalis), American star drum (Stellifer lanceolatus), black drum (Pogonias cromis), silver perch (Bairdiella chrysoura), and spotted seatrout (Cynoscion nebulosus) (e.g., Hill et al., 1987; Nieland \& Wilson, 1993; Sprague et al., 2000; Collins et al., 2001; Montie et al., 2015). Sciaenids most likely evolved the ability to produce acoustic signals in order to communicate in turbid estuaries where the water visibility is minimal (Holt et al., 1981; Moyle \& Cech, 1988; Holt, 2008). In this family, fish produce sound by contracting a sonic muscle against an inflated swim bladder (reviewed in Fine \& Parmentier, 2015). In most Sciaenids, males are the prominent sound producers; however, in the Atlantic croaker and black drum, both male and female have sonic muscles and call (Hill et al., 1987; Tellechea et al., 2010). In most cases, sound production is associated with defending territory and reproduction. 
92 However, there are still some questions on how exactly calling and spawning are correlated in

93

94

95

96

97

many sound-producing species (e.g., Luczkovich et al., 1999a; Locascio et al., 2012).

Research studies have illustrated that patterns of fish calling overlap with patterns of reproductive senescence in the wild (Connaughton \& Taylor, 1995). By performing acoustic recordings and plankton tows simultaneously, studies have also shown an association between calling and spawning (Mok \& Gilmore, 1983; Saucier \& Baltz, 1993; Luczkovich et al., 1999a; Aalbers \& Drawbridge, 2008). These comparisons are necessary if acoustic metrics are to be used as a means to monitor fish spawning patterns. These data are difficult to acquire in the wild because of the uncertainties associated with ensuring that the collected eggs are from the same fish that are calling (Locascio et al., 2012). In the field, it is likely that egg counts are affected by water currents, predator activity, and plankton tow efficiency. Captive studies can remove these variables. A few studies have mimicked wild environmental conditions and examined the relationship between calling and spawning in the laboratory (Guest \& Lasswell, 1978; Connaughton \& Taylor, 1996; Montie et al., 2016). Recently, Montie et al. (2016) collected quantitative data to better understand the association between sound production, call structure, and eggs released in a captive brood stock of red drum. In this study, red drum spawned only on evenings when males called. In addition, more eggs were collected on evenings when red drum calls were longer in duration and contained more pulses.

In the present study, our main objective was to examine the relationship between acoustic metrics (i.e., the amount of calling and sound pressure levels) and the number of eggs collected in laboratory tanks containing spotted seatrout. Spotted seatrout are found in estuaries from Cape Cod, Massachusetts to Key West, Florida and from southwest Florida to southern Mexico in the Gulf of Campeche (Welsh \& Breder, 1924; Mather, 1952; Tabb, 1966). Spotted seatrout are 
115 group-synchronous spawners with a long spawning season from April to September along the

116 South Atlantic and the Gulf of Mexico coasts (Overstreet, 1983; Brown-Peterson et al., 1988;

117 McMichael and Peters, 1989; Saucier and Baltz, 1993; Brown-Peterson and Warren, 2001;

118 Brown-Peterson et al., 2002; Nieland et al., 2002; Brown-Peterson, 2003; Roumillat and

119 Brouwer, 2004). It was estimated that spotted seatrout in age classes 1-3 spawn every 4.7, 4.2,

120 and 4 days, respectively, in Charleston Harbor, South Carolina (Roumillat and Brouwer, 2004).

121 Tabb (1966) was the first to report that male spotted seatrout use acoustic signals that are

122 associated with reproductive activity. Mok and Gilmore (1983) discovered that male spotted

123 seatrout produce four major sound types, which were all recorded at spawning sites in Indian

124 River Lagoon, Florida. These calls were designated as i) a "grunt" followed by a series of

125 "knocks", ii) "aggregated grunts", iii) "long grunt"; and iv) a rapid series of short pulses known

126 as the "staccato". Females do not have a sonic muscle and do not produce sound (Mok and

127 Gilmore, 1983). It is well known that spotted seatrout form large mating aggregations (i.e., leks).

128 These aggregations produce higher sound pressure levels ( $>50 \mathrm{~dB}$ to $90 \mathrm{~dB}$ re $1 \mu \mathrm{Pa}$ at $3 \mathrm{~m})$ as

129 compared to the levels of individual callers ( $<30 \mathrm{~dB}$ re $1 \mu \mathrm{Pa}$ at $3 \mathrm{~m})$ (Gilmore, 2003). It is

130 speculated that this combined acoustic energy derived from a male aggregation increases the

131 number of receptive spawning females attracted to the lek (Gilmore, 2003). In the present study,

132 our specific objectives were to: (i) briefly describe the different call types of captive spotted

133 seatrout; (ii) investigate if captive fish showed daily rhythms in calling; (iii) determine if a

134 quantitative relationship exists between the amount of calling and the quantity of eggs released;

135 and (iv) examine if certain call types or changes in call structure were associated with spawning

136 productivity. These data provide supportive evidence that acoustic metrics can be used to better

137 understand reproductive rhythms over various time scales (i.e., daily, tidal, lunar, seasonal, 
138 yearly, and decadal) and that these metrics can be used to investigate the impacts of natural and

139 anthropogenic stressors on these reproductive patterns.

140

141 MATERIALS AND METHODS

142 For this study, sexually mature spotted seatrout were placed into three separate, $3.67 \mathrm{~m}$

143 diameter, $1.7 \mathrm{~m}$ deep, circular fiberglass tanks (i.e., Tank 1, Tank 2, and Tank 3) (Fig. 1A). Each

144 tank was filled with settled, sterilized Charleston Harbor seawater and contained individual re-

145 circulating aquaculture systems outfitted with UV sterilizers, protein fractionators, and bead

146 filters. Fish numbers, sexes, and sizes for each tank are provided in Table 1. Tank 1 housed

147 seven males and seven females. Tank 2 contained eight males and seven females. Tank 3 had

148 three males and thirteen females. Three times a week, fish were fed equal parts of shrimp, squid,

149 and Boston mackerel (Scomber scombrus). Tank temperatures were individually controlled.

150 Water temperature and photoperiod were held at a cycle that encouraged spawning and followed

151 a natural reproductive season for spotted seatrout in South Carolina (Roumillat and Brouwer,

152 2004; Montie et al., 2015). However, in Tank 1, the temperature was maintained at $27.8^{\circ} \mathrm{C}$ and

153 the photoperiod was left at $14.5 \mathrm{~h}$ light until late November to extend the spawning season and

154 provide more data points to test the association between calling and spawning. Acoustic

155 monitoring occurred from April 13 to December 19, 2012 for Tank 1 and from April 13 to

156 November 21, 2012 for Tanks 2 and 3. Different fish compositions, temperature cycles, and

157 photoperiods among the tanks were set by SCDNR to investigate how these variables affected

158 reproductive success.

159 In order to collect floating eggs from spawns, the large tanks contained a surface,

160 skimming port that emptied into an egg collection tank following methods previously described 
161 (Montie et al., 2016). Each morning, the nets were checked for eggs. If present, the eggs were

162 harvested and transferred to a $15 \mathrm{~L}$ Artemia hatching cone, which allowed separation into fertile

163 (i.e., floating) and non-fertile (i.e., sinking) eggs. Once separated, fertile and non-fertile eggs

164 were enumerated volumetrically using graduated cylinders. In all results reported in this study,

165 the quantity of eggs collected refers to the sum of the fertile and non-fertile eggs. This work was

166 part of the SCDNR restocking program for spotted seatrout and did not require an IACUC. No

167 fish were harmed or sacrificed in this study.

168 We deployed acoustic loggers (DSG-Oceans, Loggerhead Instruments, Sarasota, FL,

169 USA, www.loggerhead.com) into each tank following methods previously described (Montie et

170 al., 2016). The DSG-Ocean was positioned vertically in the tank center (i.e., 3.67 diameter tanks)

171 inside a cement mold and attached to a piece of vertical rebar, which was embedded in the

172 cement mold (Fig. 1B). The DSG-Ocean was approximately $1.83 \mathrm{~m}$ from the side of the tank and

$1731.05 \mathrm{~m}$ from the water surface. Observations of fish in tanks indicated that the average

174 swimming patterns occurred counterclockwise at mid-depth (i.e., $0.85 \mathrm{~m}$ ) approximately half

175 way between the hydrophone and the tank side (Fig. 1C).

176 When recording fish sounds in tanks, there is always the possibility that reverberation,

177 resonance, and tank size can affect the sounds recorded. For example, Parmentier et al. (2014)

178 provided some evidence that fiberglass tanks (i.e., $6 \mathrm{~m}^{3}$ and $13 \mathrm{~m}^{3}$ ) can affect sound duration,

179 pulse duration, pulse period, and dominant frequency. Akamatsu et al. (2002) illustrated that

180 dominant frequency, sound pressure level, and power spectrum recorded in very small, $170 \mathrm{~L}$

181 (i.e., $0.17 \mathrm{~m}^{3}$ ) rectangular glass tanks were significantly distorted compared to the original

182 acoustic signal. Nonetheless, most captive studies that focus on sound production live with

183 resonance and distortion effects present in tanks (e.g., Connaughton and Taylor, 1996; Montie et 
184 al., 2016). Akamatsu et al. (2002) do provide a practical procedure for correcting the

185 measurements of fish sounds in small tanks. These guidelines indicate that the targeted sound

186 frequency (i.e., the frequency of the fish calls) should be different than the minimum resonant

187 frequency $\left(\mathrm{f}_{\min }\right)$ of the tank. In addition, the hydrophone should be positioned within the

188 attenuation distance (D) of the sound source to minimize possible distortion.

189 Even though Akamatsu et al. (2002) used tanks that were much smaller than the tanks

190 used in the present study (i.e., 0.17 compared to $17.88 \mathrm{~m}^{3}$ ), we calculated $\mathrm{F}_{\min }$ and $\mathrm{D}$ using the

191 guidelines and equations provided by Akamatsu et al. (2002). We determined that $\mathrm{F}_{\min }=541 \mathrm{~Hz}$,

192 which was different than the expected peak frequency of spotted seatrout chorusing in the wild

193 (i.e., $239 \mathrm{~Hz}$; E. Montie, unpublished data); thus possible resonance was minimal. We also

194 determined that $\mathrm{D}=1.48 \mathrm{~m}$, which was smaller than the radius of the tank and the maximum

195 possible distance of a calling fish from the hydrophone (i.e., $1.83 \mathrm{~m}$ ); thus some distortion was

196 possible. We minimized this distortion effect by placing the recorders in the center of the tank.

197 Therefore, calling fish ranged anywhere from $0 \mathrm{~m}$ (i.e., when a fish was immediately next to

198 recorder) to $1.83 \mathrm{~m}$ (i.e., when a fish was located next to the side of the tank). As stated

199 previously, observations of fish in these tanks indicated that the average swimming patterns

200 occurred counterclockwise half way between the hydrophone and the tank side (i.e., $\sim 1 \mathrm{~m}$ from

201 the hydrophone). Therefore, generally speaking, calling fish were less than $1 \mathrm{~m}$ from the

202 hydrophone, which was within the attenuation distance of the sound source and distortion was

203 minimized.

204

The DSG-Ocean contains a High Tech Inc. hydrophone (i.e., $-185 \mathrm{dBV} \mu \mathrm{Pa}^{-1}$ sensitivity)

attached to a microcomputer circuit board with a gain of $20 \mathrm{~dB}$ that is powered by $24 \mathrm{D}$-cell

alkaline batteries. This equipment is housed in a cylindrical PVC housing (i.e., $0.65 \mathrm{~cm}$ length, 
$20711.5 \mathrm{~cm}$ diameter). The DSG board is calibrated with a $0.1 \mathrm{~V}$ (peak) frequency sweep from 2 -

$208100 \mathrm{kHz}$. For this experiment, DSG-Oceans were set to a sampling rate of $50 \mathrm{kHz}$ and were

209 scheduled to record sound for 2 minutes every 20 minutes. Files were saved as 'DSG files' on a

210128 GB SD-card. Recorders were retrieved nine times during the experiment, once on May $5^{\text {th }}$,

211 May $7^{\text {th }}$, May $25^{\text {th }}$, June $25^{\text {th }}$, July $23^{\text {rd }}$, August $24^{\text {th }}$, September $21^{\text {st }}$, and October $26^{\text {th }}$ to

212 download data and change batteries and again on November $21^{\text {st }}$ and December $19^{\text {th }}$ to

213 download final files. In Tank 1, acoustic recordings were not collected between 16:40, May $18^{\text {th }}$

214 and 19:40, May 22 ${ }^{\text {nd }}, 2012$ due to recorder malfunction. After each data retrieval, the 'DSG files'

215 were downloaded to a network drive and batch converted into 'wav files' using DSG2wav(C)

216 software (Loggerhead Instruments, Sarasota, FL, USA).

217 We manually counted the quantity of calls within each 'wav file' by viewing the files in

218 Adobe Audition (Adobe Systems Incorporated, San Jose, CA, USA, www.adobe.com). In our

219 captive study, we grouped the "grunt followed by knocks" and "aggregated grunts" observed by

220 Mok \& Gilmore (1983) together because of their similarity in call structure and described these

221 calls as "drums" to avoid confusion with the "grunt". We classified the "long grunt" as the

222 "grunt", while the "staccato" strictly followed the description provided by Mok \& Gilmore

223 (1983). For each tank, we determined the number of "grunts", "drums", and "staccatos" per day

224 by adding up the calls that occurred between 18:00 and 06:00, which was the time range in

225 which most calling occurred. The 'wav' file with the most abundant calls was used to determine

226 the mean number of pulses in a "staccato" call as well as the mean duration for that specific day.

227 The pulse number was evaluated by manually counting each individual pulse in a "staccato". The

228 "staccato" duration was determined by manually subtracting the time of call termination from the

229 time of call initiation. 


$$
\begin{aligned}
& \mathrm{S}=\mathrm{h}+\mathrm{g}+20 \log 10\left(1 / \mathrm{V}_{\mathrm{adc}}\right) ; \\
& \mathrm{b}=20 \log 10\left(\operatorname{sqrt}\left(\operatorname{mean}\left(\mathrm{y}^{\wedge} 2\right)\right)\right) ; \\
& \mathrm{a}=\mathrm{b}-\mathrm{S} ;
\end{aligned}
$$

where $\mathrm{a}=$ calibrated sound level in $\mathrm{dB}$ re $1 \mu \mathrm{Pa} ; \mathrm{b}=$ uncorrected signal; $\mathrm{S}=$ correction factor; $\mathrm{h}$ = hydrophone sensitivity (i.e., $-185 \mathrm{dBV} \mu \mathrm{Pa}^{-1}$ ) ; $\mathrm{g}=\mathrm{DSG}$ gain (i.e., 20); $\mathrm{V}_{\mathrm{adc}}=$ analog-to-digital or recorder and tank maintenance were not included in SPL analysis. From these data, we then calling were 148 (i.e., 139 calls detected), 146 (i.e., 76 calls detected), and 138 (i.e., 67 calls detected) $\mathrm{dB}$ re $1 \mu \mathrm{Pa}$, respectively. illustrated for "drums", "grunts", and "staccatos". Then, the number of calls and received SPLs, spawning productivity, and call characteristics for each tank were summarized. Using Pearson correlation analysis, we investigated the relationship between all calls (i.e., sum of "grunts", 
254 "drums", and "staccatos") and received SPLs for each tank. To examine the relationship between

255 simulated seasonal parameters and calling, we plotted water temperature, photoperiod, and the

256 number of calls versus date. To investigate the daily rhythms of calling, we determined the mean

257 number of "drums" for each time interval during the $14.5 \mathrm{~h}$ of light photoperiod for each tank.

258 We performed a quantitative, stepwise investigation to determine the relationship

259 between calling and spawning. In order to examine the overlap of sound production and

260 reproductive events, our first approach was to plot the total number of calls per day and the

261 quantity of eggs collected (i.e., the next morning) versus the date for each tank. The next step

262 was to perform autocorrelation analysis (i.e., at -5 to +5 day lags) to examine the relationship

263 between calling variables (i.e., number of calls and received SPL) and eggs collected. This

264 analysis determined if the correlation between calling and spawning was the highest when these

265 two variables were aligned within the same timeframe as compared to a negative or positive lag.

266 Then, we used logistic regression to test whether or not the likelihood that spotted seatrout

267 tended to spawn increased as calling (i.e., the total quantity of calls between 15:40 and 00:00)

268 and received SPLs (i.e., the mean SPL between 15:40 and 00:00) increased. The categorical

269 dependent variable was spawning $(0=$ no; $1=$ yes $)$ and the predictor variables were calling or

270 received SPL. Next, we used linear regression analysis to investigate if more productive spawns

271 were associated with more calling or higher sound levels. We performed two separate linear

272 regressions. One regression analysis included all the data, and the other analysis excluded the

273 days when there were no eggs. We also performed logistic regression to test whether or not the

274 likelihood that spotted seatrout tended to spawn increased as "staccato" calls increased in

275 duration and pulse number.. To test the relationship between call structure and spawning 
276 productivity, we performed linear regression analysis with call duration or pulse number as the

277 independent variable and the quantity of eggs as the dependent variable.

278

279 RESULTS

280

Types of Spotted Seatrout Calls Detected in Captivity

281

Spotted seatrout produced three call types. These calls were characterized as "drums",

282

“grunts”, or "staccatos” (Fig. 2; Mok \& Gilmore, 1983; Sprague et al., 2000; Walters et al.,

2009). We provided a very coarse description of these call types and leave a more detailed

description of frequency range, peak frequency, sound pressure level, call duration, number of

pulses in a call, pulse duration, and pulse interval for each of the call types to future

investigations. What we report here is that most of the acoustic energy of calling occurred

pulses $(\mathrm{n}>5)$ (Fig. 2A, B, E). A grunt call was composed of a single pulse displaying multiple

harmonics (Fig. 2A, C, F). A drum call was composed of one to five pulses (Fig. 2A, D, G). In

all tanks, the number of drums, grunts, and staccatos were positively correlated with each other

(Pearson Correlation Test; $P<0.05$ for all comparisons). Sound pressure levels during periods

when fish were calling were higher than the background noise levels when spotted seatrout were not calling (Fig. 3B, E, H). In all tanks, drums were the most frequently produced followed by grunts and then staccatos (Table 2; Fig. 4). Sound pressure level and the total number of calls

(i.e., sum of drums, grunts, and staccatos) were positively correlated (Pearson Correlation Test; $r$

\section{Seasonal and Daily Patterns in Calling}


Three general patterns in calling were observed over the simulated reproductive season.

300 First, fish calling occurred in all tanks (Table 2; Fig. 4). Second, the amount of calling differed

301 among tanks (Tank $1>$ Tank $2>$ Tank 3; Table 2; Fig. 4). Third, sound production changed with

302 photoperiod and water temperature adjustments. Maximal calling occurred when the photoperiod

303 shifted to $14.5 \mathrm{~h}$ of light, and the temperature increased to $27.7^{\circ} \mathrm{C}$. Sound production began to

304 decrease as the temperature dropped below $27.7^{\circ} \mathrm{C}$, and the light cycle changed to $12 \mathrm{~h}$ light per

305 day. In Tank 3, spotted seatrout calling was more sporadic (Fig. 4C). The general pattern was

306 that calling increased as the light cycle shifted from 12.5 to $14.5 \mathrm{~h}$ light per day and as the

307 temperature increased to $27.8^{\circ} \mathrm{C}$. Between $9 / 21 / 2012$ and $11 / 8 / 2012$, calling was more prevalent

308 than other time periods. Sound production began to diminish as the temperature dropped below

$30924.0{ }^{\circ} \mathrm{C}$ on $11 / 14 / 2012$. In Tanks $1-3$, rapid fluctuations in water temperature affected sound

310 production; rapid elevations in temperature increased calling rates, while rapid declines in

311 temperature decreased calling (Fig. 4).

312 In all tanks, spotted seatrout showed daily rhythms in sound production (Fig. 5).

313 Generally, calling began once the lights turned off (i.e., 17:45). The highest number of drums

314 occurred at 21:20 in Tank 1;21:00 in Tank 2; and 20:40 in Tank 3 (Fig. 5). The number of

315 grunts, staccatos, and received SPLs followed similar patterns.

316

317 The Association between Calling and Spawning

318 In this captive experiment, our data indicated that sound production served an important

319 function in courtship. First, we discovered that successful reproductive events happened only on

320 evenings in which spotted seatrout produced sound (Fig. 6). On many evenings, male spotted

321 seatrout did call and no spawning was observed, but spawning never happened without a 
322 significant increase in sound production. Second, autocorrelation analysis showed that the

323 greatest correlation between sound production and eggs released happened on the same evening

324 when the lag $=0$ (Fig. 7). Third, logistic regression results indicated that the likelihood that

325 spotted seatrout reproduced was significantly related to calling variables (i.e., number of calls

326 and received SPL) (Table 3; Fig. 8). Fourth, there was some evidence that spawning was more

327 productive when spotted seatrout called more frequently. When all data were included in

328 regression analysis, more productive spawns (i.e., larger egg numbers) were associated with

329 more calling and higher received SPLs (Table 4). If the days when no eggs were collected were

330 removed from statistical tests, then the amount of calling in relation to egg deposition was not

331 significant (Table 4). However, in Tanks 1 and 3, the relationships between SPL and the number

332 of eggs collected were significant, even when the non-spawning events were removed from

333 linear regressions (Table 4). Fifth, tanks with more sound production had more spawns (Tank $1>$

334 Tank 2 > Tank 3; Table 1). Tanks with more calling and higher mean SPLs resulted in larger

335 total egg yields per gram female biomass (Fig. 9). We did test whether or not spotted seatrout

336 were more likely to spawn when staccato calls contained more pulses and calls were longer in

337 duration, but we found no significant difference.

338

339 DISCUSSION

340 Spotted Seatrout Call Types in Captivity

341 Spotted seatrout call types in this study were similar to the types of calls described in

342 other studies (Mok \& Gilmore, 1983; Luczkovich et al., 1999b; Sprague et al., 2000; Luczkovich

343 et al., 2008). Mok \& Gilmore (1983) recorded and classified spotted seatrout sounds into four

344 call types: i) "grunt followed by knocks"; ii) "aggregated grunts"; iii) "long grunt"; and iv) 
345 "staccato". In wild studies, these four call types have been recorded at spawning locations

346 (Gilmore, 2003). In our captive study, we grouped the "grunt followed by knocks" and

347 "aggregated grunts" together because of their similarity in call structure and described these calls

348 as "drums" to avoid confusion with the "grunt". We classified the "long grunt" as the "grunt",

349 while the "staccato" strictly followed the description provided by Mok \& Gilmore (1983). In the

350 present captive study, all of these call types (i.e., "drums", "grunts", and "staccatos") were

351 associated with courtship behavior and spawning. We do realize a more thorough analysis of

352 each call type would be beneficial, but this type of analysis is outside the scope of this paper.

353 Received SPL correlated with the sum of the drums, grunts, and staccatos (i.e., the total

354 number of calls). Calculating SPL of the entire 'wav' file provides a way to calculate the overall

355 acoustic energy. This metric is a function of the amount of calling, the number of pulses in a call,

356 the call duration, the acoustic energy of each call, and how far away the fish is from the recorder.

357 These findings are important, because in the wild, it is not feasible to count the number of calls

358 in a chorusing aggregation due to overlapping calls. Calculating SPLs becomes especially

359 important for monitoring wild spawning aggregations over long time periods. The deployment of

360 autonomous recorders generates thousands of files and having a MATLAB code that

361 automatically calculates received SPLs is faster than manually reviewing acoustic files. One

362 major drawback in determining received SPL in the wild is that the intensity depends on the

363 distance from the spawning aggregation, which is often unknown. Another challenge is that the

364 SPL measurement can contain acoustic energy from other sources because the frequency range

365 of a chorusing aggregation often overlaps with the frequency ranges of sounds produced by other

366 marine organisms (i.e., snapping shrimp and other fish species) and boats. 


\section{Seasonal and Daily Patterns in Calling}

369

370

371

372

373

374

375

376

377

378

379

380

381

382

384

385

386

387

388

389

390

We discovered that calling increased when the water temperature rose to around $27^{\circ} \mathrm{C}$ and when the photoperiod increased to $14.5 \mathrm{hrs}$ of light. These parameters mimicked the temperature and daylight hours observed during the summer, which is the spawning season in the southeast (Luczkovich et al., 1999b; Roumillat and Brouwer, 2004; Luczkovich et al., 2008). In North and South Carolina, sound production of spotted seatrout has been observed from May to September (Riekerk, Tyree, \& Roumillat, 1997; Luczkovich et al., 2008; Montie et al., 2008). Before the onset of spawning, circulating testosterone levels most likely increase and this change causes the sonic muscle to increase in weight. These hormonal and anatomical changes have been observed in weakfish as calling reaches its peak (Connaughton \& Taylor 1994;

Connaughton \& Taylor, 1995). An important point of this captive study is that it illustrates how deploying fixed, passive acoustic platforms (i.e., DSG-Oceans) can precisely define spawning seasons and relationships to water temperature. Tracking these sounds in the wild can provide exact spawning start and end dates, the length of the spawning season, and spawning frequency, which are necessary parameters in order to determine how climate change may shift or interrupt the timing of seasonal reproduction.

We found that wild caught spotted seatrout exhibited daily patterns of calling, which began when the lights turned off and reached maximum activity three hours later. Atlantic croaker, sand seatrout (Cynoscion arenarius), and red drum show similar calling patterns with sound production increasing at laboratory-simulated dusk (Holt et al., 1985; Montie et al., 2015). In Charleston Harbor, South Carolina, spotted seatrout calling occurred from 18:00 to 22:00 hs with a peak in the late evening (Riekerk, Tyree, \& Roumillat, 1997). In Pamlico Sound, North Carolina, spotted seatrout drumming activity began after sunset (21:00 hs), peaked at 22:00 hs, 
391 and ended at 23:00 hs (Luczkovich et al., 2008). In Barataria, Caminada, and Eastern Timbalier

392 Bay Systems of Louisiana, Saucier and Baltz (1993) showed that spotted seatrout sound

393 production occurred from 17:00 to $01: 00$ hs and that $92 \%$ of the drumming occurred between

394 19:00 and 23:00 hs. The daily patterns of calling observed in the present study were comparable

395 to the patterns reported in these wild studies. Sciaenids most likely spawn at dusk to limit the

396 predation on eggs by many juvenile and adult fishes (Holt et al., 1985).

397

In all tanks, rapid temperature changes within the simulated reproductive season affected

calling (Fig. 4). Generally, rapid rises in temperature increased calling rates, while rapid declines

in temperature decreased calling. Similarly, we found that wild caught red drum held in

laboratory tanks exhibited similar temperature dependent behaviors (Montie et al., 2016). Other

401

studies with different fish species revealed similar findings. In a study with tiger bass (Terapon

jarbua), higher temperatures increased the amount of calling and the number of pulses in a call

403

404

405

406

407

408

409

410

411

412

413

(Schneider, 1967). In oyster toadfish (Opsanus tau), increases in water temperature increased the number of courtship calls and their fundamental frequency (Fine, 1978). In captive weakfish, rises in water temperature increased the mean SPL, the mean number of pulses, and the mean frequency of calls (Connaughton et al., 2000). Our findings and past studies indicate that changes in water temperature as low as $2^{\circ} \mathrm{C}$ can affect calling rates, which could in turn affect the ability of a reproductively active female to find a spawning aggregation. Thus, climate change could have important implications on the acoustic communication of fish, spawning, and reproductive output.

In the wild, there is some evidence that spotted seatrout calling and spawning are associated with the lunar cycle. Gilmore (1994) discovered that spotted seatrout calling occurred most often on the full moon or within three to four days after the full moon. However, our 
414 preliminary studies have indicated different patterns than the findings observed by Gilmore

415 (1994). Since 2013, our lab has been monitoring the underwater soundscape at three stations in

416 the May River, South Carolina using DSG-Ocean recorders. In the May River, our studies have

417 indicated that longer chorusing episodes with earlier start times occur on the second and fourth

418 quarter lunar cycles rather than on the third cycle (i.e., full moon) as observed by Gilmore (1994)

419 (E. Montie, unpublished data). In the present captive study, a lunar light cycle was not included

420 in the simulated reproductive season. Not including this natural rhythm may have altered the

421 natural spawning patterns observed in the wild. This may partly explain why sound production

422 and egg deposition were not more tightly correlated in the present captive study.

424 Sound Production Influences Spawning Success

425 Spotted seatrout were more likely to spawn when male fish called more frequently. In

426 addition, there was some evidence that spawning was more productive when rms SPLs were

427 higher. In Tanks 1 and 3, we discovered a statistically significant positive relationship between

428 SPL and egg deposition. In our captive red drum study, we found a much stronger relationship

429 between the amount of calling and the number of eggs collected (Montie et al., 2016). In the

430 present study, our findings did not indicate that the call type or call composition played a

431 differential role in spawning success. However, we found that the call structure was important in

432 spawning success of wild caught red drum (Montie et al., 2016). In that study, we demonstrated

433 that the number of pulses in a call was higher and the mean call duration was longer on evenings

434 when spawning did occur (Montie et al., 2016). In the present study, we did not examine, in

435 detail, how changes in call structure affected spawning success. It would be interesting to

436 examine the acoustic characteristics of each call type and determine if these characteristics are 
437 different between non-spawning and spawning events. These characteristics could include

438 frequency range, peak frequency, sound pressure level, call duration, number of pulses in a call,

439 pulse duration, and pulse interval for each of the call types. However, this type of analysis is

440 outside the scope of this paper and will be the focus of future work. A more thorough

441 examination may find that the complex repertoire of calls of spotted seatrout may affect

442 spawning success.

443 We observed that sound production varied among tanks. More calling was detected in

444 Tanks 1 and 2 as compared to Tank 3 (Table 2; Fig. 4). Tanks 1 and 2 contained more males than

445 Tank 3, while Tank 3 contained more females (Table 1). Only male spotted seatrout have a sonic

446 muscle and produce sound, which explains why more calling was detected in Tanks 1 and 2 as

447 compared to Tank 3. In addition, spotted seatrout in Tanks 1 and 2 spawned more often and

448 produced more eggs per gram of female biomass than seatrout in Tank 3, despite having close to

449 twice the number of females in Tank 3 (Table 1; Fig. 9). These findings may indicate that having

450 more males that are acoustically active in a spawning aggregation are key factors in enhancing

451 reproductive output and sustaining populations.

452 Other studies performed in captive environments have qualitatively demonstrated a

453 relationship between calling and reproductive events in red drum, weakfish, and white seabass

454 (Atractoscion nobilis) (Guest and Laswell, 1978; Connaughton and Taylor, 1996; Lowerre-

455 Barbieri et al., 2008; Aalbers and Drawbridge, 2008). In wild studies, plankton tows and acoustic

456 recordings performed on the same night and location have revealed an association between

457 sound production and spawning (Mok \& Gilmore, 1983; Saucier \& Baltz, 1993; Connaughton \&

458 Taylor, 1995; Luczkovich et al., 1999a). In black drum, silver perch, and spotted seatrout in

459 Indian River Lagoon, Florida, peak calling occurred between 17:00 and 22:00 hours, which 
460 coincided with the presence of eggs and larvae in the water column (Mok \& Gilmore, 1983). In

461 studies with wild spotted seatrout in the Barataria, Caminada, and eastern Timbalier Bay systems

462 of Louisiana, tows downstream of drumming aggregations contained two to three times more

463 eggs in comparison to tows upstream (Saucier and Baltz, 1993). In studies with weakfish and

464 silver perch aggregations in Pamlico Sound, North Carolina, SPLs of aggregations positively

465 correlated with the presence of "sciaenid-type" eggs (Luczkovich et al., 1999a).

466 What exact role does sound production play in the spawning process of sciaenids? Male

467 calling most likely aids the attraction of a gravid female to a spawning location as suggested by

468 Connaughton \& Taylor (1996). Larger aggregations of males and more calling increases the overall SPL of the chorus, which can propagate outward over larger distances from the source

470 and attract females from further locations. In addition, drumming may contain information 471 regarding male fitness (Connaughton \& Taylor, 1996). In our study with captive red drum, 472 spawns were more productive on evenings when calls were longer in duration and contained 473 more pulses (Montie et al., 2016); however, this association was not found in the present study

474 with captive spotted seatrout. In some sciaenids, the variability in call structure may indicate that 475 males compete with each other to be chosen by females (i.e., intersexual selection). It is possible 476 that the good gene model in intersexual selection (i.e., females choose males based on physical 477 characteristics or abilities that may display some genetic advantage) plays a major role in 478 courtship behaviors and spawning success. For example, it has been shown that female gray tree 479 frogs (Hyla versicolor) prefer to mate with male frogs that advertise long mating calls (Welch et 480 al., 1998). Because offspring fathered by long-calling males outperformed their half-siblings

481 fathered by short-calling males (i.e., with regards to larval survival, growth, and time to 482 metamorphosis), Welch et al. (1998) concluded that the duration of a male's mating call is 
483 indicative of the male's overall genetic quality. More research is necessary to better understand

484 the formation, maintenance, and dynamics of spotted seatrout spawning aggregations and the 485 exact function of male calling.

486

487

488

489

490

491

492

493

494

495

496

497

498

499

500

501

502

503

504

505

\section{CONCLUSIONS}

Spotted seatrout were more likely to spawn when male fish called more frequently. Yet, there were several times during the recording period when there was calling but no spawning occurred. Some aspects of spotted seatrout reproductive biology may explain this observation. Most estimates of spawning frequency suggest that female spotted seatrout spawn once every 4 to 5 days, as reviewed by Brown-Peterson (2003). In addition, there is some evidence that spotted seatrout calling and spawning are associated with the lunar cycle, which was not controlled for in the present study.

Nonetheless, our findings indicate that we can use acoustic metrics, with confidence, to predict spawning potential. Passive acoustics can be used to find the location of spawning aggregations, determine spawning start and end dates, and possibly estimate maximal values of spawning frequency within a reproductive season. These findings are significant because plankton tows may not accurately reflect spawning locations since egg capture is likely affected by predator activity, water currents, and tow efficiency. Instead, passive acoustics could be used to monitor spotted seatrout reproduction. Future studies can use this captive study as a model to record the estuarine soundscape precisely over long time periods to better understand how human-made stressors (e.g., climate change, noise pollution, and chemical pollutants) may affect spawning patterns. 
506

507

508

509

510

511

512

513

514

515

516

517

518

519

520

521

522

523

524

525

526

527 Brown-Peterson NJ, Thomas P, Arnold C. 1988. Reproductive biology of the spotted seatrout, 528 Cynoscion nebulosus, in South Texas. Fishery Bulletin 86:373-387.

\section{ACKNOWLEDGEMENTS}

We thank the staff of SCDNR for husbandry care of spotted seatrout. We would also like to thank the following students and staff from USCB for their help in collection of data, analysis, and editing: Matt Hoover, Rebecca Rawson, Steven Vega, Michael Powell, Alishia Zyer, and Dr. Brian Canada.

\section{REFERENCES}

Aalbers SA, Drawbridge MA. 2008. White seabass spawning behavior and sound production.

Transactions of the American Fisheries Society 137:542-550.

Akamatsu T, Okumura T, Novarini N, Yan HY. 2002. Empirical refinements applicable to the recording of fish sounds in small tanks. Journal of Acoustical Society of America 112:30723082.

Amorim MCP. 2006. Diversity of sound production in fish. In Communication in Fishes

(Ladich, F., Collin, S. P., Moller, P., \& Kapoor, B. G., eds), pp. 71-105. New Hampshire:

Science Publishers.

Brown-Peterson NJ. 2003. The reproductive biology of spotted seatrout. In Biology of the Spotted Seatrout (S. A. Bortone, ed.) p. 99-133. CRC Press, Boca Raton, FL. 
530 Brown-Peterson NJ, Peterson MS, Nieland DL, Murphy MD, Taylor RG, Warren JR.

531 2001. Reproductive biology of female spotted seatrout, Cynoscion nebulosus, in the Gulf of

532 Mexico: differences among estuaries? Environmental Biology of Fishes 63:405-415.

533

534 Brown-Peterson NJ, Warren JR. 2002. The reproductive biology of spotted seatrout, Cynoscion 535 nebulosus, along the Mississippi Gulf coast. Gulf of Mexico Science 19:61-73.

536

537 Collins MR, Callahan BM, Post WC. 2001. Spawning aggregations of recreationally important

538 Sciaenid species in the Savannah Harbor: spotted seatrout Cynoscion nebulosus, red drum

539 Sciaenops ocellatus, weakfish Cynoscion regalis, and black drum Pogonias cromis. Final report

540 to Georgia Ports Authority by the South Carolina Department of Natural Resources, Marine

541 Resources Research Institute. Charleston, SC.

542

543 Connaughton MA, Taylor MH. 1994. Seasonal cycles in the sonic muscles of the weakfish,

544 Cynoscion regalis. Fishery Bulletin 92:697-703.

545

546 Connaughton MA, Taylor MH. 1995. Seasonal and daily cycles of sound production associated 547 with spawning in weakfish Cynoscion regalis. Environmental Biology of Fishes 42:233-240.

548

549 Connaughton MA, Taylor MH. 1996. Drumming, courtship, and spawning behavior in captive 550 weakfish, Cynoscion regalis. Copeia 1:195-199. 
552 Connaughton MA, Taylor MH, Fine ML. 2000. Effects of fish size and temperature on weakfish

553 disturbance calls: implications for the mechanism of sound generation. The Journal of

554 Experimental Biology 203:1503-1512.

555

556 Fine ML. 1978. Seasonal and geographical variation of the mating call of the oyster toadfish

557 Opsanus tau. Oecologia 36:45-57.

558

559 Fine ML, Burns NM, Harris TM. 1990. Ontogeny and sexual dimorphism of sonic muscle in 560 oyster toadfish. Canadian Journal of Zoology 68:1374-1381.

561

562 Fine ML, Parmentier E. 2015. Mechanisms of fish sound production. In Sound Communication 563 in Fishes Animal Signals and Communication 4 (Ladich, F., ed.), pp. 77-126. Springer-Verlag 564 Wien.

565

566

Fish MP, Mowbray WH. 1970. Sounds of the Western North Atlantic Fishes. John Hopkins 567 University Press.

568

569 Gilmore RG Jr. 1994. Environmental parameters associated with spawning, larval dispersal, and 570 early life history of the spotted seatrout, Cynoscion nebulosus (Cuvier), Final Program Rev.,

571 Contract No. LCD 347. Mar. Res. Inst., Fla. Dept. Environ. Protection, St. Petersburg, FL.

572

573 Gilmore RG. 2003. Sound production and communication in the spotted seatrout. In Biology of 574 the Spotted Seatrout (S. A. Bortone, ed.) p. 99-133. CRC Press, Boca Raton, FL. 
576 Guest WC, Lasswell JL. 1978. A note on courtship behaviour and sound production of red drum.

577 Copeia 1978:337-338.

578

579 Hill GL, Michael LF, Musick J. 1987. Ontogeny of the sexually dimorphic sonic muscle in three 580 sciaenid species. Copeia 3:708-713.

581

582 Holt J, Godbout R, Arnold CR. 1981. Effects of temperature and salinity on egg hatching and 583 larval survival of red drum, Sciaenops ocellata. Fishery Bulletin 79:569-573.

584

585 Holt GJ, Holt SA, Arnold CR. 1985. Diel periodicity of spawning in sciaenids. Marine Ecology 586 Progress Series 27:1-7.

587

588

Holt SA. 2008. Distribution of red drum spawning sites identified by a towed hydrophone array.

589 Transactions of the American Fisheries Society 137:551-561.

590

591 Kinsler LE, Frey AR, Coppens AB, Sanders JV. 1999. Fundamentals of Acoustics, $4^{\text {th }}$

592 edition. Wiley, NJ.

593

594 Locascio JV, Mann DA. 2011. Diel and seasonal timing of sound production by black drum 595 (Pogonias cromis). Fishery Bulletin 109:327-338.

596 
597 Locascio JV, Burghart S, Mann DA. 2012. Quantitative and temporal relationships of egg 598 production and sound production by black drum Pogonias cromis. Journal of Fish Biology 599 81:1175-1191.

600

601

Lowerre-Barbieri SK, Barbieri LR, Flanders JR, Woodward AG, Cotton CF, Knowlton MK. 602 2008. Use of passive acoustics to determine red drum spawning in Georgia waters. Transactions 603 of the American Fisheries Society 137:562-575.

604

605

Luczkovich JJ, Sprague MW, Johnson SE, Pullinger RC. 1999a. Delimiting spawning areas of 606 weakfish Cynoscion regalis (family sciaenidae) in Pamlico Sound North Carolina using passive 607 hydroacoustic surveys. Bioacoustics 10:143-160.

608

Luczkovich JJ, Sprague MW, Johnson SE, Pullinger RC, Jenkins T, Hutchinson M. $1999 \mathrm{~b}$.

Characterization of critical spawning habitats of weakfish, spotted seatrout, and red drum in

Pamlico Sound using hydrophone surveys. North Carolina Department of Environment and

612

Natural Resources, Division of Marine Fisheries, Morehead City, NC. 128 p.

613

614

Luczkovich JJ, Pullinger RC, Johnson SE, Sprague MW. 2008. Identifying sciaenid critical 615 spawning habitats by the use of passive acoustics. Transactions of the American Fisheries 616 Society 137:576-605.

617

618 Mann DA, Lobel PS. 1995. Passive acoustic detection of sounds produced by the damselfish, 619 Dascyllus albisella (Pomacentridae). Bioacoustics 6:199-213. 
621 Mann DA, Grothues TM. 2009. Short-term upwelling events modulate fish sound production at a 622 mid-Atlantic ocean observatory. Marine Ecology Progress Series 375:65-71.

623

624 Mann DA, Locascio JV, Schärer M, Nemeth M, Appeldoorn R. 2010. Sound production by red 625 hind (Epinephelus guttatus) in spatially segregated spawning aggregations. Aquatic Biology 626 10:149-154.

627

628 Maruska KP, Mensinger AF. 2009. Acoustic characteristics and variations in grunt vocalizations 629 in the oyster toadfish Opsanus tau. Environmental Biology of Fishes 84:325-337.

630

631 Mather FJ. 1952. Sport fishes of the vicinity of the Gulf of Honduras, certain Caribbean Islands, 632 and Carmen, Mexico. Proceedings of the Gulf and Caribbean Fisheries Institute, $4^{\text {th }}$ Annual 633 Session, 118-129.

634

635 McMichael RH, Peters KM. 1989. Early life-history of spotted seatrout, Cynoscion nebulosus 636 (Pisces: Sciaenidae), in Tampa Bay, Florida. Estuaries 12:98-110.

637

638 Merchant ND, Fristrup KM, Johnson MP, Tyack PL, Witt MJ, Blondel P, Parks SE. Measuring 639 acoustic habitats. Methods in Ecology and Evolution 6:257-265. 
641 Mok HK, Gilmore RG. 1983. Analysis of sound production in estuarine aggregations of 642 Pogonias cromis, Bairdiella chrysoura, and Cynoscion nebulosus (sciaenidae). Bulletin of the 643 Institute of Zoology 22:157-186.

644

645 Montie EW, Vega S, Powell M. 2015. Seasonal and spatial patterns of fish sound production in 646 the May River, South Carolina. Transactions of the American Fisheries Society 144:705-716.

647

648 Montie EW, Kehrer C, Yost J, Brenkert K, O’Donnell T, Denson MR. 2016. Long-term

649 monitoring of captive red drum Sciaenops ocellatus reveals that calling incidence and structure 650 correlate with egg deposition. Journal of Fish Biology 88:1776-1795.

651

652 Moyle PB, Cech JJ. 1988. Fishes: An Intoduction to Ichthyology. Prentice, Hall.

653

654 Nieland DL, Wilson CA. 1993. Reproductive biology and annual variation of reproductive 655 variables of black drum in the northern Gulf of Mexico. Transactions of the American Fisheries 656 Society 122:318-327.

657

658 Nieland DL, Thomas RG, Wilson CA. 2002. Age, growth and reproduction of spotted seatrout in 659 Barataria Bay, Louisiana. Transactions of the American Fisheries Society 131:245-259.

660

661 Overstreet RM. 1983. Aspects of the biology of the spotted seatrout, Cynoscion nebulosus, in 662 Mississippi. Gulf Research Reports Supplemental 1:1-43. 
664 Parmentier E, Lecchini D, Frederich B, Mann D. 2009. Sound production in four Dascyllus

665 species: phyletic relationships? Biological Journal of the Linnean Society 97:928-940.

666

667 Parmentier E, Tock J, Falguière JC, Beauchaud M. 2014. Sound production in Sciaenops

668 ocellatus: preliminary study for the develpment of acoustic cues in aquaculture. Aquaculture

669 432: 204-211.

670

671 Riekerk GHM., Tyree SJ, Roumillat WA. 1997. Spawning times and locations of spotted

672 seatrout in the Charleston Harbor Estuarine System from acoustic surveys, 21 p. Final Report to

673 Charleston Harbor Project, Bureau of Ocean and Coastal Resources Management, South

674 Carolina Department of Health and Environmental Control, 1362 McMillan Ave., Charleston, 675 SC 29405.

676

677 Roumillat WA, Brouwer MC. 2004. Reproductive dynamics of female spotted seatrout

678 (Cynoscion nebulosus) in South Carolina. Fishery Bulletin 102:473-487.

679

680 Rowe S, Hutchings J. 2006. Sound production by Atlantic cod during spawning. Transactions of 681 American Fisheries Society 135:529-538.

682

683 Saucier MH, Baltz DM. 1993. Spawning site selection by spotted seatrout, Cynoscion nebulosus, 684 and black drum, Pogonias cromis, in Louisiana. Environmental Biology of Fishes 36:257-272. 685 
686 Schneider H. 1967. Morphology and physiology of sound-producing mechanisms of teleost 687 fishes. In Marine Bio-Acoustics (Tavolga, W. N., ed.). pp. 135-158. Oxford: Pergamon Press. 688

689 Širović A, Cutter GR, Butler JL, Demer DA. 2009. Rockfish sounds and their potential use for 690 population monitoring in the Southern California Bight. ICES Journal of Marine Science 66:981691990.

692

693 Sprague MW, Luczkovich JJ, Pullinger RC, Johnson SE, Jenkins T, Daniel HJ III. 2000. Using 694 spectral analysis to identify drumming sounds of some North Carolina fishes in the family 695 Sciaenidae. Journal of the Elisha Mitchell Society 116:124-145.

696

697 Tabb DC. 1966. The estuary as a habitat for spotted seatrout, Cynoscion nebulosus. In: Smith, R. 698 F. (ed). A symposium on estuarine fisheries. American Fisheries Society Specifications 699 Publications 3:59-67.

700

701 Tavolga WN. 1958. Underwater sounds produced by two species of toadfish, Opsanus tau and 702 Opsanus beta. Bulletin of Marine Science 8: 278-284.

703

704 Tellechea JS, Norbis W, Olsson D, Fine ML. 2010. Calls of the black drum (Pogonius chromis:

705 Sciaenidae): Geographical differences in sound production between Northern and Southern

706 Hemisphere populations. Journal of Experimental Zoology 313A:1-8. 
708 Walters S, Lowerre-Barbieri S, Bickford J, Mann D. 2009. Using a passive acoustic survey to

709 identify spotted seatrout spawning sites and associated habitat in Tampa Bay, Florida.

710 Transactions of the American Fisheries Society 138:88-98.

711

712 Welch AM, Semlitsch RD, Gerhardt HC. 1998. Call duration as an indicator of genetic quality in 713 male gray tree frogs. Science. 280:1928-1930.

714

715 Welsh WW, Breder CM Jr. 1924. Contributions to life histories of Sciaenidae of the Eastern 716 United States coast. Bulletin of the U. S. Bureau of Fisheries 48:41-117.

\section{FIGURE LEGENDS}

719 Figure. 1. (A) Spotted seatrout (Cynoscion nebulosus) were held in three separate, $3.67 \mathrm{~m}$ 720 diameter fiberglass tanks (i.e., Tank 1, Tank 2, and Tank 3) with individual recirculating 721 aquaculture systems equipped with UV sterilizers, protein fractionators, and bead filters. Floating 722 eggs were collected from a surface, skimming port in the side of the tank that drained into an egg 723 collection tank equipped with a 250-micron mesh net. (B) Placement of DSG-Ocean acoustic 724 recorders relative to the tank's dimensions. (C) Placement of DSG-Oceans relative to the general 725 swimming patterns of the fish.

726

727 Figure. 2. Different call types produced by wild caught spotted seatrout (Cynoscion nebulosus) 728 held in captivity. Spotted seatrout produced three different call types. These calls were 729 characterized as "drums", "grunts", or "staccatos" following similar nomenclature published in 730 other studies (Mok \& Gilmore, 1983; Sprague et al., 2000; Walters et al., 2009). (A) A 
731 continuous spectrogram illustrating a staccato (labeled 1), grunts (labeled 2), and a series of

732 drums (labeled 3). Time domain of (B) a staccato, (C) a grunt, and (D) a drum call. Power

733 spectral density (PSD) plots of (E) a staccato, (F) a grunt, and (G) a drum call. The sample rate

734 was $50 \mathrm{kHz}$. In panel A, the spectrogram was created using Adobe Audition with a spectral

735 resolution of 2048 and time duration of $10 \mathrm{~s}$. Brighter colors correspond to higher sound pressure

736 levels. Time domain and PSD figures correspond to the calls outlined in solid white lines in

737 panel A. PSDs of background noise in the tanks were calculated from recordings when fish were

738 not present in the tanks. PSDs were determined using a FFT size of 1024 samples, which

739 corresponded to a frequency resolution of $48.8 \mathrm{~Hz}$.

740

741 Figure 3. Representative spectrograms (A, D, G), instantaneous sound pressure levels (B, E, H), 742 and power spectral density calculations (C, F, I) of an entire 2 min wav file for each tank during 743 an evening in which male spotted seat trout called and females spawned. Tank $1=2,680,000$

744 eggs were collected the next morning; Tank $2=7,110,000$ eggs; and Tank $3=2,580,000$ eggs.

745 The sample rate was $50 \mathrm{kHz}$. The spectrograms were created using Adobe Audition with a 746 spectral resolution of 2048 and time duration of $120 \mathrm{~s}$. Brighter colors correspond to fish calling 747 and higher sound pressure levels. Instantaneous SPLs and PSDs in this figure were calculated 748 between 1 and $2000 \mathrm{~Hz}$ using a FFT size of 50,000 samples, which corresponded to a frequency 749 resolution of $1 \mathrm{~Hz}$. Corresponding background SPLs and PSDs for each tank were performed on 7502 min wav files in which calling was not detected. These background noise files were selected as 751 closely in time as possible to the represented fish choruses. 
753 Figure 4. Sound production by wild caught spotted seatrout (Cynoscion nebulosus) held in

754 captivity throughout the entire study period. The number of drums, grunts, and staccatos in each

7552 min 'wav file' was manually counted by an observer and plotted versus date with

756 corresponding water temperatures for (A) Tank 1, (B) Tank 2, and (C) Tank 3. The numbers

757 above the horizontal arrows indicate the number of hours of light present in the respective

758 photoperiod. Boxes indicate rapid fluctuations in water temperature. Generally, abrupt rises in

759 temperature were followed by an increase in calling, while abrupt drops were followed by a

760 decrease in the amount of calling.

761

762 Figure 5. Daily patterns of sound production by spotted seatrout (Cynoscion nebulosus) in (A)

763 Tank 1; (B) Tank 2; and (C) Tank 3. To examine these patterns, we determined the mean number

764 of drums for each time interval (e.g., $12: 00$ to $12: 02 ; 12: 20$ to $12: 22 ; 12: 40$ to $12: 42,13: 00$ to

765 13:02, etc.) during the $14.5 \mathrm{~h}$ light photoperiod. The grey box indicates the time span of darkness

766 during the $14.5 \mathrm{~h}$ light photoperiod. Standard deviations are reported as vertical bars.

767

768 Figure 6. Sound production and spawning of wild caught spotted seatrout (Cynoscion nebulosus)

769 held in captivity throughout the entire study period. Calls per day and the number of eggs

770 collected (i.e., the next morning) were plotted versus the date for (A) Tank 1, (B) Tank 2, and

771 (C) Tank 3.

772

773 Figure 7. Autocorrelation analysis was used to determine the correlation between calling

774 variables (i.e., number of calls and sound pressure level or SPL) and eggs collected at -5 to +5

775 day lags in wild caught spotted seatrout (Cynoscion nebulosus) held in captivity. (A) Tank 1 - 
776 number of calls, (B) Tank 1 - SPL, (C) Tank 2 - number of calls, (D) Tank 2 - SPL, (E) Tank 3

777 - number of calls, (F) Tank 3 - SPL. The dotted lines represent the 95\% confidence interval.

778

779 Figure 8. A comparison of sound production of wild caught spotted seatrout (Cynoscion

780 nebulosus) held in captivity for non-spawning and spawning periods. For each tank, (A) the

781 number of drums; (B) the number of grunts; (C) the number of staccatos; and (D) the sound

782 pressure level (SPL) were compared for non-spawning and spawning nights. No spawn = blue

783 bar; spawn = red bar. Standard errors are reported.

784

785

Figure 9. Tank comparisons of sound production and spawning for wild caught spotted seatrout

786

(Cynoscion nebulosus) held in captivity. The total number of eggs collected per gram of female

787

biomass versus (A) the total number of calls per days monitored and (B) the mean received

788

sound pressure level (SPL) for Tank 1, Tank 2, and Tank 3. The total number of calls per days

789

monitored was calculated by summing the total number of drums, grunts, and staccatos from

790

18:00 to 06:00 throughout the entire study period and then dividing this value by the number of

791 days monitored. The mean SPL for each tank was determined by averaging all the 2 min SPLs

792 from 18:00 to 06:00 over the entire study period. 


\section{Table $\mathbf{1}$ (on next page)}

Summary of information for spotted seatrout (Cynoscion nebulosus) in each tank. 
Table 1. Summary of information for spotted seatrout (Cynoscion nebulosus) in each tank.

\begin{tabular}{|c|c|c|c|c|}
\hline Tank Information & Tank 1 & Tank 2 & Tank 3 & Means $\pm \mathrm{SE}$ \\
\hline No. of males & 7 & 8 & 3 & $6 \pm 2$ \\
\hline Mean weight of males $(\mathrm{g})$ & $1,126 \pm 320$ & $1,314 \pm 281$ & $1,200 \pm 194$ & $1,213 \pm 55$ \\
\hline Mean length of males (mm) & $469 \pm 41$ & $500 \pm 36$ & $484 \pm 29$ & $484 \pm 9$ \\
\hline No. of females & 7 & 7 & 13 & $9 \pm 2$ \\
\hline Mean weight of females $(\mathrm{g})$ & $1,298 \pm 194$ & $1,953 \pm 670$ & $1,403 \pm 209$ & $1,551 \pm 203$ \\
\hline Mean length of females (mm) & $497 \pm 29$ & $543 \pm 70$ & $502 \pm 28$ & $514 \pm 15$ \\
\hline Timeframe for data collection & $4 / 13 / 12-12 / 19 / 12$ & $4 / 13 / 12-11 / 21 / 12$ & $4 / 13 / 12-11 / 21 / 12$ & NA \\
\hline No. of days monitored & 250 & 222 & 222 & $231 \pm 9$ \\
\hline Mean water temperature $\left({ }^{\circ} \mathrm{C}\right)$ & 26.4 & 24.9 & 26.0 & $25.8 \pm 0.4$ \\
\hline
\end{tabular}

$\mathrm{NA}=$ not applicable

Means \pm standard deviations for individual tanks.

Means \pm standard errors of all four tanks. 
Table 2 (on next page)

Tank summary of sound production and spawning events for captive spotted seatrout (Cynoscion nebulosus). 
Table 2. Tank summary of sound production and spawning events for captive spotted seatrout (Cynoscion nebulosus).

\begin{tabular}{|c|c|c|c|c|}
\hline Tank Information & Tank 1 & Tank 2 & Tank 3 & Means $\pm \mathrm{SE}$ \\
\hline No. of spawns & 81 & 13 & 3 & $32 \pm 25$ \\
\hline No. of spawns / days monitored & 0.32 & 0.06 & 0.01 & $0.13 \pm 0.10$ \\
\hline Eggs collected & $72,486,000$ & $13,630,000$ & $4,160,000$ & $30,092,000 \pm 21,372,558$ \\
\hline Eggs collected / days monitored & 289,944 & 61,396 & 18,739 & $123,360 \pm 84,198$ \\
\hline No. of drums & 227,659 & 123,729 & 15,532 & $122,307 \pm 61,240$ \\
\hline No. of drums / days monitored & 911 & 557 & 70 & $513 \pm 244$ \\
\hline Mean drums between 18:00 to $06: 00$ (no spawning) & $708 \pm 516$ & $491 \pm 467$ & $59 \pm 123$ & $419 \pm 191$ \\
\hline Mean drums between 18:00 to 06:00 (spawning) & $1,376 \pm 538$ & $1,624 \pm 325$ & $856 \pm 442$ & $1,285 \pm 226$ \\
\hline No. of grunts & 13,109 & 6,105 & 1,786 & $7,000 \pm 3,299$ \\
\hline No. of grunts / days monitored & 52 & 28 & 8 & $29 \pm 13$ \\
\hline Mean grunts between 18:00 to $06: 00$ (no spawning) & $41 \pm 32$ & $25 \pm 24$ & $7 \pm 15$ & $24 \pm 10$ \\
\hline Mean grunts between 18:00 to 06:00 (spawning) & $78 \pm 45$ & $69 \pm 28$ & $63 \pm 51$ & $70 \pm 4$ \\
\hline No. of staccatos & 3,139 & 1,565 & 22 & $1,575 \pm 900$ \\
\hline No. of staccatos / days monitored & 13 & 7 & $<1$ & $10 \pm 2$ \\
\hline Mean staccatos between 18:00 to 06:00 (no spawning) & $8 \pm 8$ & $6 \pm 10$ & $<1$ & $7 \pm 1$ \\
\hline Mean staccatos between18:00 to 06:00 (spawning) & $24 \pm 14$ & $29 \pm 20$ & $3 \pm 4$ & $19 \pm 8$ \\
\hline Mean SPL between 18:00 to 06:00 (no spawning) & $120 \pm 3$ & $116 \pm 3$ & $113 \pm 2$ & $116 \pm 2$ \\
\hline Mean SPL between 18:00 to 06:00 (spawning) & $124 \pm 3$ & $122 \pm 2$ & $118 \pm 4$ & $121 \pm 2$ \\
\hline
\end{tabular}

$\mathrm{SPL}=$ received sound pressure level $(\mathrm{dB}$ re $1 \mathrm{uPa})$

Means \pm standard deviations reported for individual tanks.

Means \pm standard errors of all four tanks. 


\section{Table 3 (on next page)}

Results of logistic regression analysis that tested whether or not the amount of calling and sound pressure level (SPL) were significant predictors of spotted seatrout spawning. 
Table 3. Results of logistic regression analysis that tested whether or not the amount of calling and sound pressure level (SPL) were significant predictors of spotted seatrout (Cynoscion nebulosus) spawning. In all cases, the dependent variable was spawning $(0=$ no; $1=$ yes $)$. No. of calls and mean SPL are measurements per evening from 15:40 to 0:00. The overall model evaluation used the log-likelihood statistical test.

$\begin{array}{lllll}\text { Tank } & \text { Predictor Variable } & \text { Logistic Model } & z & P\end{array}$

\begin{tabular}{|c|c|c|c|c|c|c|c|c|}
\hline & & & & & & $x^{2}$ & df & $\mathrm{P}$ \\
\hline Tank 1 & No. of drums & $\operatorname{Logit}(y)=-2.926+0.002 x$ & 7.073 & $<0.001$ & 1.002 & 70.216 & 1 & $<0.001$ \\
\hline Tank 1 & No. of grunts & $\operatorname{Logit}(y)=-2.154+0.026 x$ & 5.873 & $<0.001$ & 1.026 & 46.545 & 1 & $<0.001$ \\
\hline Tank 1 & No. of staccatos & $\operatorname{Logit}(y)=-2.555+0.132 x$ & 7.495 & $<0.001$ & 1.141 & 94.895 & 1 & $<0.001$ \\
\hline Tank 1 & Total calls & $\operatorname{Logit}(y)=-2.983+0.002 x$ & 7.123 & $<0.001$ & 1.002 & 72.215 & 1 & $<0.001$ \\
\hline Tank 1 & Mean SPL & $\operatorname{Logit}(y)=-42.521+0.344 x$ & 6.793 & $<0.001$ & 1.411 & 66.415 & 1 & $<0.001$ \\
\hline Tank 2 & No. of drums & $\operatorname{Logit}(y)=-12.522+0.008 x$ & 4.172 & $<0.001$ & 1.008 & 64.594 & 1 & $<0.001$ \\
\hline Tank 2 & No. of grunts & $\operatorname{Logit}(y)=-5.902+0.066 x$ & 4.130 & $<0.001$ & 1.068 & 31.143 & 1 & $<0.001$ \\
\hline Tank 2 & No. of staccatos & $\operatorname{Logit}(y)=-4.033+0.090 x$ & 4.573 & $<0.001$ & 1.094 & 26.282 & 1 & $<0.001$ \\
\hline Tank 2 & Total calls & $\operatorname{Logit}(y)=-13.197+0.008 x$ & 4.131 & $<0.001$ & 1.008 & 66.084 & 1 & $<0.001$ \\
\hline Tank 2 & Mean SPL & $\operatorname{Logit}(\mathrm{y})=-103.059+0.841 \mathrm{x}$ & 4.381 & $<0.001$ & 2.318 & 39.716 & 1 & $<0.001$ \\
\hline Tank 3 & No. of drums & $\operatorname{Logit}(y)=-7.385+0.010 x$ & 2.784 & 0.005 & 1.010 & 20.540 & 1 & $<0.001$ \\
\hline Tank 3 & No. of grunts & $\operatorname{Logit}(y)=-5.653+0.055 x$ & 3.257 & 0.001 & 1.057 & 11.028 & 1 & 0.001 \\
\hline Tank 3 & No. of staccatos & $\operatorname{Logit}(y)=-5.236+1.725 x$ & 2.501 & 0.012 & 5.612 & 13.344 & 1 & $<0.001$ \\
\hline Tank 3 & Total calls & $\operatorname{Logit}(y)=-7.226+0.009 x$ & 2.797 & 0.005 & 1.009 & 20.060 & 1 & $<0.001$ \\
\hline Tank 3 & Mean SPL & $\operatorname{Logit}(\mathrm{y})=-87.532+0.722 \mathrm{x}$ & 2.897 & 0.004 & 2.058 & 10.877 & 1 & 0.001 \\
\hline
\end{tabular}

$\mathrm{SPL}=$ received sound pressure level in $\mathrm{dB}$ re $1 \mu \mathrm{Pa}$. 


\section{Table 4(on next page)}

Results of linear regression analysis that tested the significance of the amount of calling and sound pressure level in relation to spawning success of spotted seatrout. 
Table 4. Results of linear regression analysis that tested the significance of the amount of calling and sound pressure level in relation to spawning success of spotted seatrout (Cynoscion nebulosus) held in captivity. In all cases, the dependent variable is the number of eggs collected.

$P$-values were statistically significant when $P<0.050$.

\begin{tabular}{|c|c|c|c|c|c|}
\hline Tank & $\begin{array}{c}\text { Independent } \\
\text { Variable }\end{array}$ & Fitted Equation & $\mathrm{r}^{2}$ & $P$ & d.f. \\
\hline Tank 1 & Total no. of calls & $y=402 x-104,522$ & 0.208 & $<0.001$ & 243 \\
\hline Tank $1^{\mathrm{A}}$ & Total no. of calls ${ }^{\mathrm{A}}$ & $y=246 x+530,897^{A}$ & $0.043^{\mathrm{A}}$ & $0.062^{\mathrm{A}}$ & $79^{\mathrm{A}}$ \\
\hline Tank 1 & Mean SPL & $y=74,752 x-8,745,163$ & 0.245 & $<0.001$ & 243 \\
\hline Tank $1^{\mathrm{A}}$ & Mean SPLA & $y=74,494 x-8,315,774^{A}$ & $0.136^{\mathrm{A}}$ & $0.001^{\mathrm{A}}$ & $79^{\mathrm{A}}$ \\
\hline Tank 2 & Total no. of calls & $y=235 x-77,917$ & 0.065 & $<0.001$ & 220 \\
\hline Tank $2^{\mathrm{A}}$ & Total no. of calls ${ }^{\mathrm{A}}$ & $y=714 x-180,228^{A}$ & $0.015^{\mathrm{A}}$ & $0.687^{\mathrm{A}}$ & $11^{\mathrm{A}}$ \\
\hline Tank 2 & Mean SPL & $y=36,452 x-4,193,465$ & 0.046 & 0.001 & 220 \\
\hline Tank $2^{\mathrm{A}}$ & Mean SPL ${ }^{A}$ & $y=230,218 x-26,911,981^{A}$ & $0.048^{\mathrm{A}}$ & $0.470^{\mathrm{A}}$ & $11^{\mathrm{A}}$ \\
\hline Tank 3 & Total no. of calls & $y=689 x+35,106$ & 0.398 & 0.003 & 220 \\
\hline Tank $3^{\mathrm{A}}$ & Total no. of calls ${ }^{\mathrm{A}}$ & $y=2,052 x-506,339^{A}$ & $0.964^{\mathrm{A}}$ & $0.122^{\mathrm{A}}$ & $1^{\mathrm{A}}$ \\
\hline Tank 3 & Mean SPL & $y=31,294 x-3,533,082$ & 0.112 & $<0.001$ & 220 \\
\hline Tank $3^{\mathrm{A}}$ & Mean SPL ${ }^{\mathrm{A}}$ & $y=250,379 x-28,201,967^{A}$ & $0.997^{\mathrm{A}}$ & $0.036^{\mathrm{A}}$ & $1^{\mathrm{A}}$ \\
\hline
\end{tabular}

$\mathrm{SPL}=$ received sound pressure level in $\mathrm{dB}$ re $1 \mu \mathrm{Pa}$.

ASeparate linear regression analysis was performed and did not include non-spawning events (i.e., when eggs collected were equal to 0 ). 


\section{Figure 1 (on next page)}

Tank setup

Figure. 1. (A) Spotted seatrout (Cynoscion nebulosus) were held in three separate, $3.67 \mathrm{~m}$ diameter fiberglass tanks (i.e., Tank 1, Tank 2, and Tank 3) with individual recirculating aquaculture systems equipped with UV sterilizers, protein fractionators, and bead filters. Floating eggs were collected from a surface, skimming port in the side of the tank that drained into an egg collection tank equipped with a 250-micron mesh net. (B) Placement of DSG-Ocean acoustic recorders relative to the tank's dimensions. (C) Placement of DSGOceans relative to the general swimming patterns of the fish. 
A

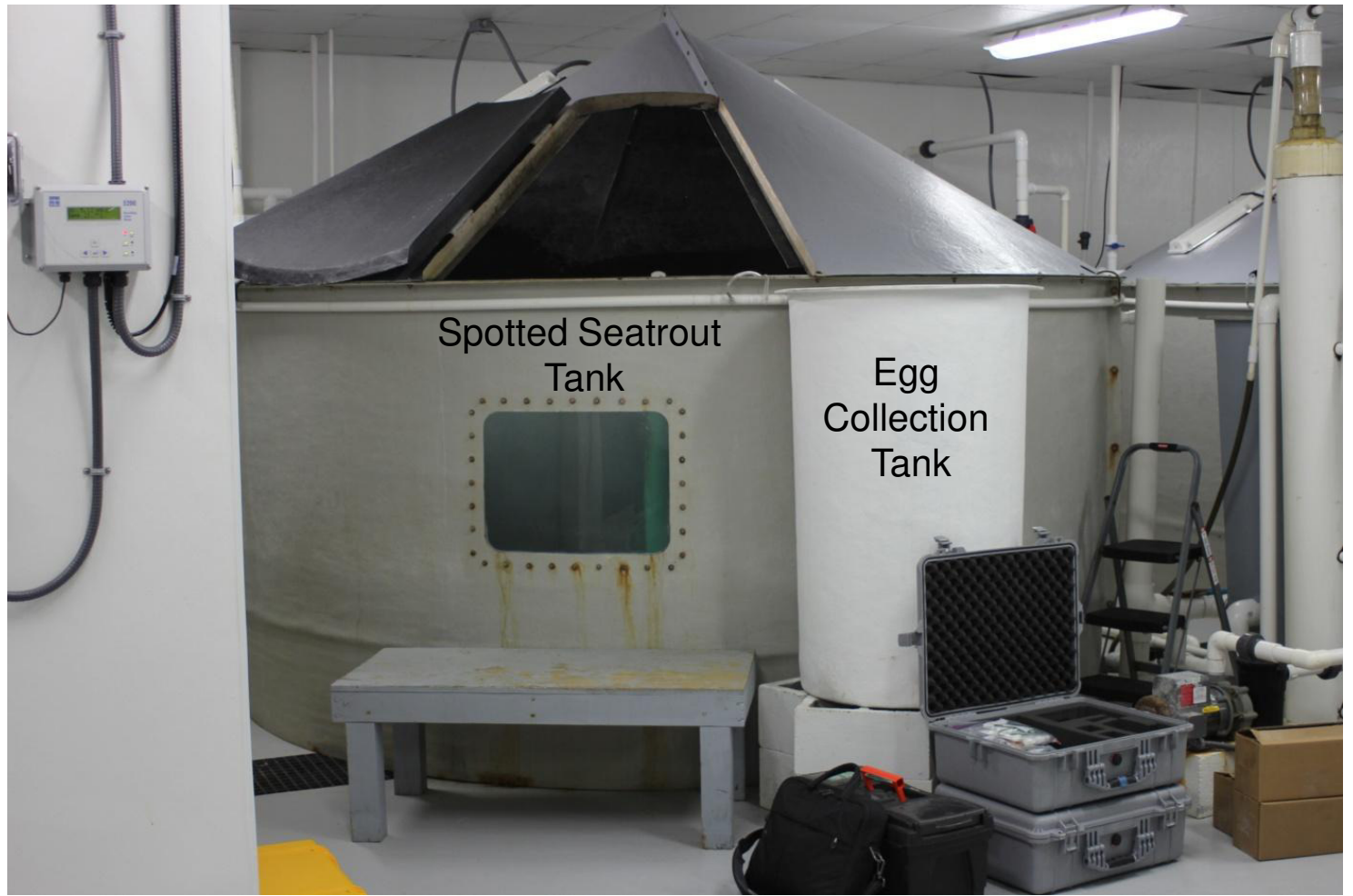

B

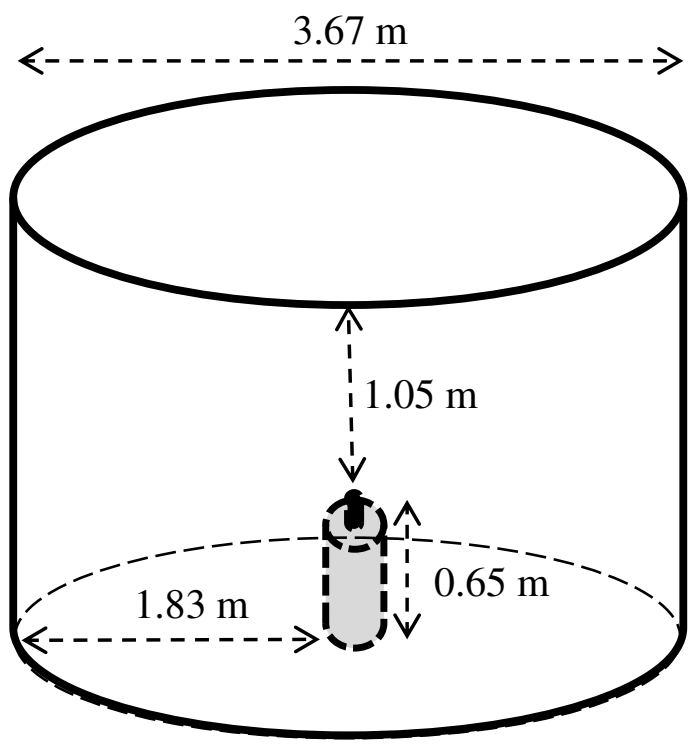

C

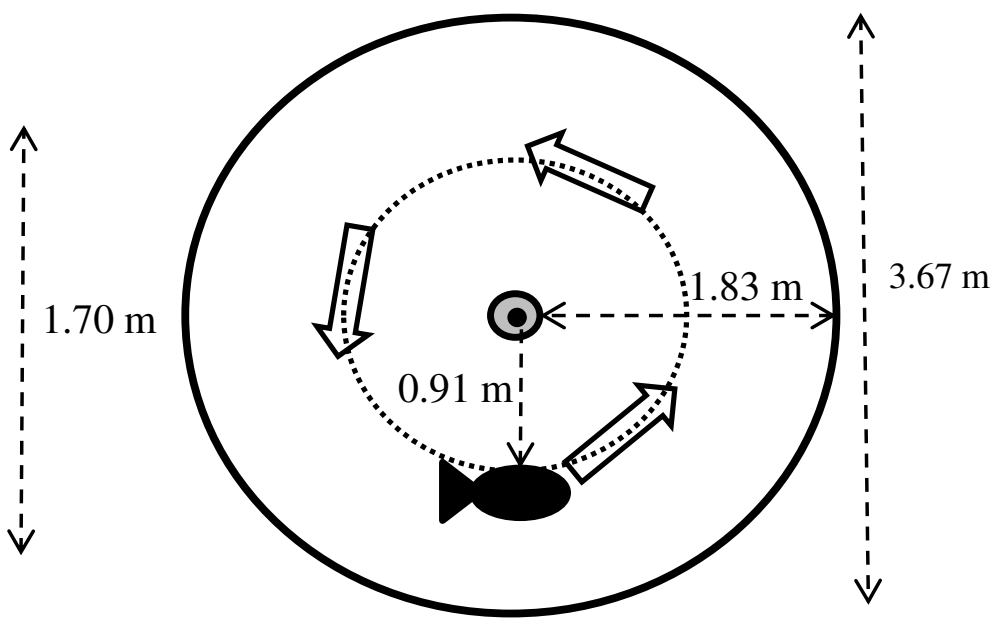




\section{Figure 2 (on next page)}

\section{Call Types}

Figure. 2. Different call types produced by wild caught spotted seatrout (Cynoscion nebulosus) held in captivity. Spotted seatrout produced three different call types. These calls were characterized as "drums", "grunts", or "staccatos" following similar nomenclature published in other studies (Mok \& Gilmore, 1983; Sprague et al., 2000; Walters et al., 2009). (A) A continuous spectrogram illustrating a staccato (labeled 1), grunts (labeled 2), and a series of drums (labeled 3). Time domain of (B) a staccato, (C) a grunt, and (D) a drum call. Power spectral density (PSD) plots of (E) a staccato, (F) a grunt, and (G) a drum call. The sample rate was $50 \mathrm{kHz}$. In panel A, the spectrogram was created using Adobe Audition with a spectral resolution of 2048 and time duration of 10 s. Brighter colors correspond to higher sound pressure levels. Time domain and PSD figures correspond to the calls outlined in solid white lines in panel A. PSDs of background noise in the tanks were calculated from recordings when fish were not present in the tanks. PSDs were determined using a FFT size of 1024 samples, which corresponded to a frequency resolution of $48.8 \mathrm{~Hz}$. 
a PeerJ

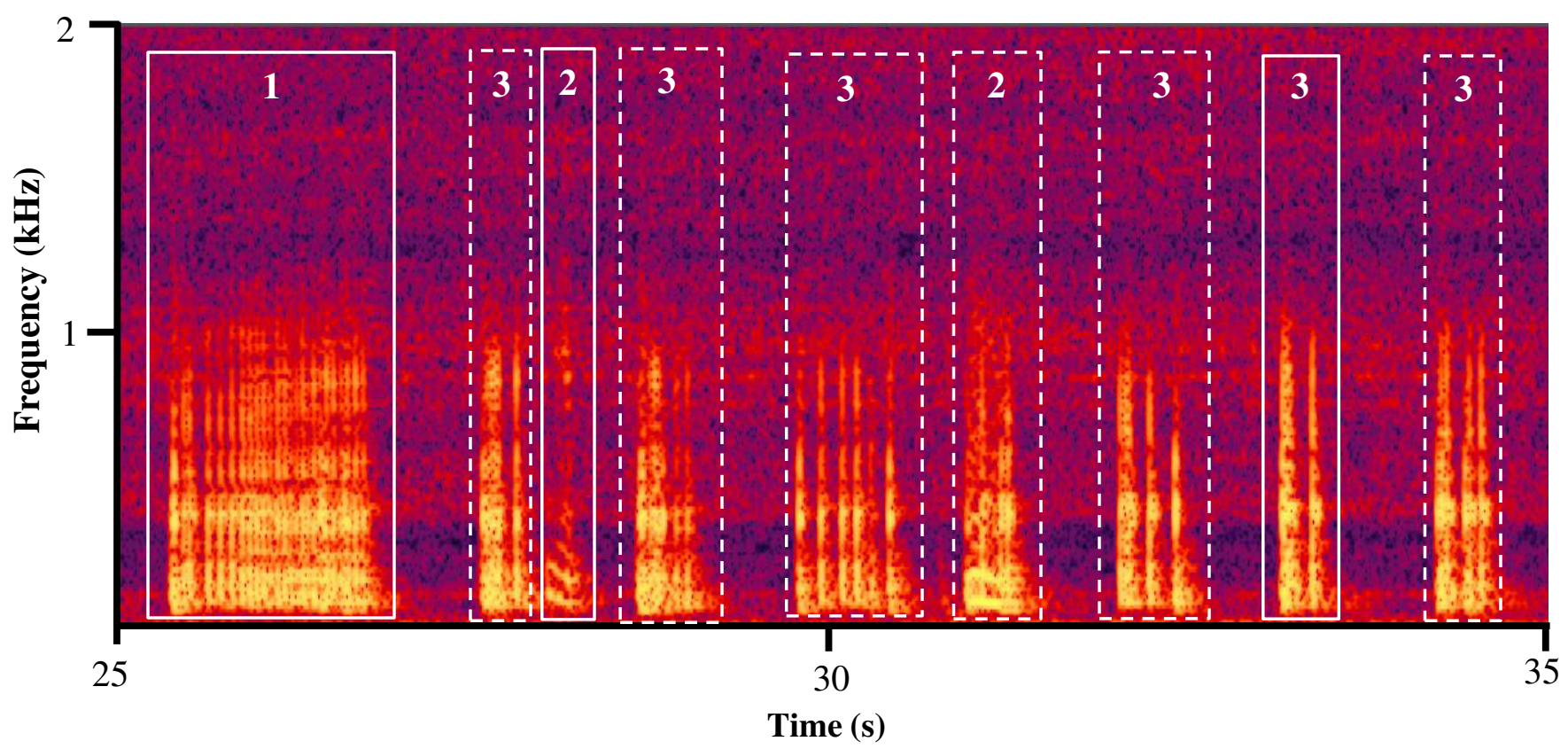

B

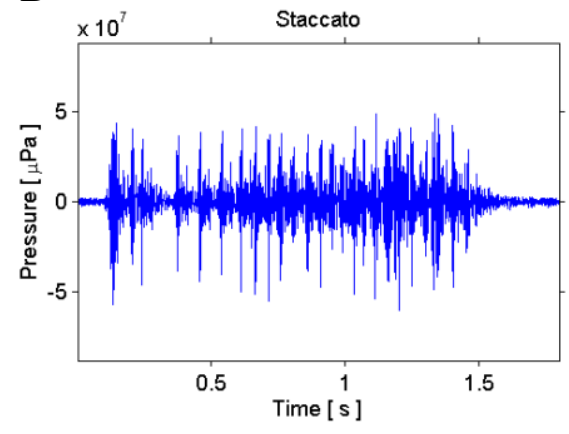

E

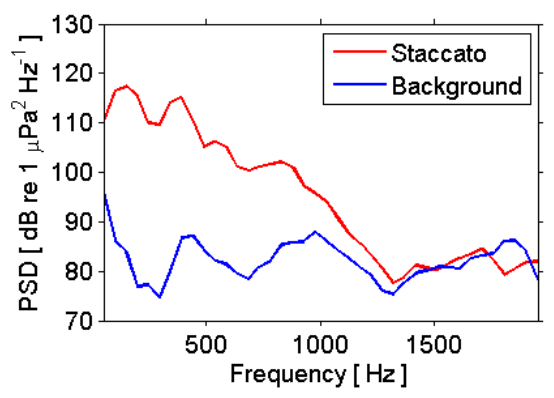

C

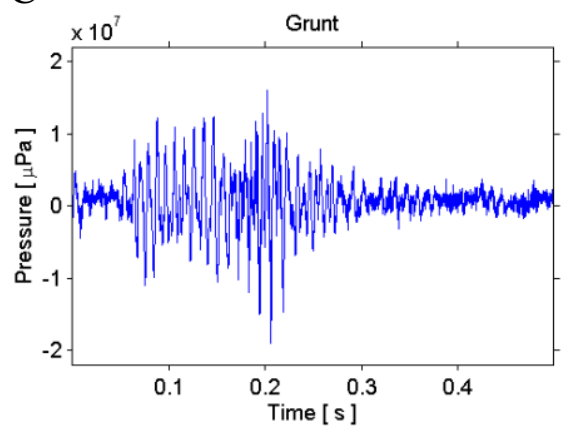

F

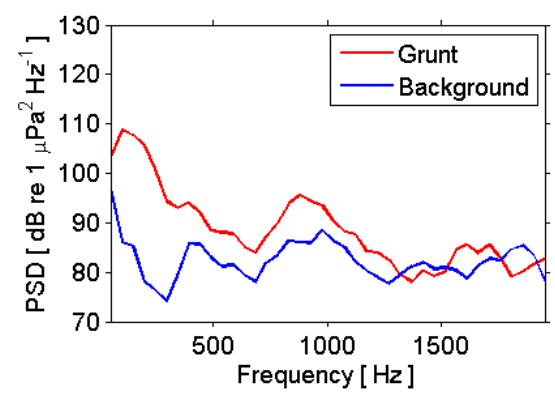

D

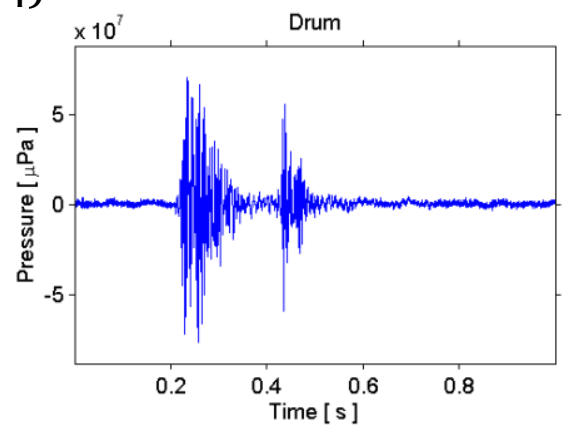

G

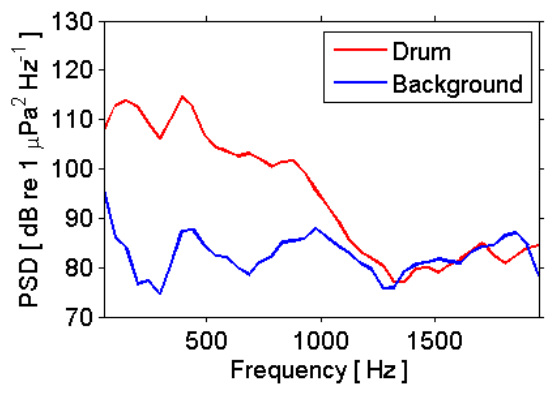




\section{Figure 3 (on next page)}

SPL and PSD comparisons between background and spotted seatrout choruses

Figure 3. Representative spectrograms $(A, D, G)$, instantaneous sound pressure levels $(B, E$, $H)$, and power spectral density calculations (C, F, I) of an entire 2 min wav file for each tank during an evening in which male spotted seat trout called and females spawned. Tank $1=$ $2,680,000$ eggs were collected the next morning; Tank $2=7,110,000$ eggs; and Tank $3=$ 2,580,000 eggs. The sample rate was $50 \mathrm{kHz}$. The spectrograms were created using Adobe Audition with a spectral resolution of 2048 and time duration of 120 s. Brighter colors correspond to fish calling and higher sound pressure levels. Instantaneous SPLs and PSDs in this figure were calculated between 1 and $2000 \mathrm{~Hz}$ using a FFT size of 50,000 samples, which corresponded to a frequency resolution of $1 \mathrm{~Hz}$. Corresponding background SPLs and PSDs for each tank were performed on 2 min wav files in which calling was not detected. These background noise files were selected as closely in time as possible to the represented fish choruses. 

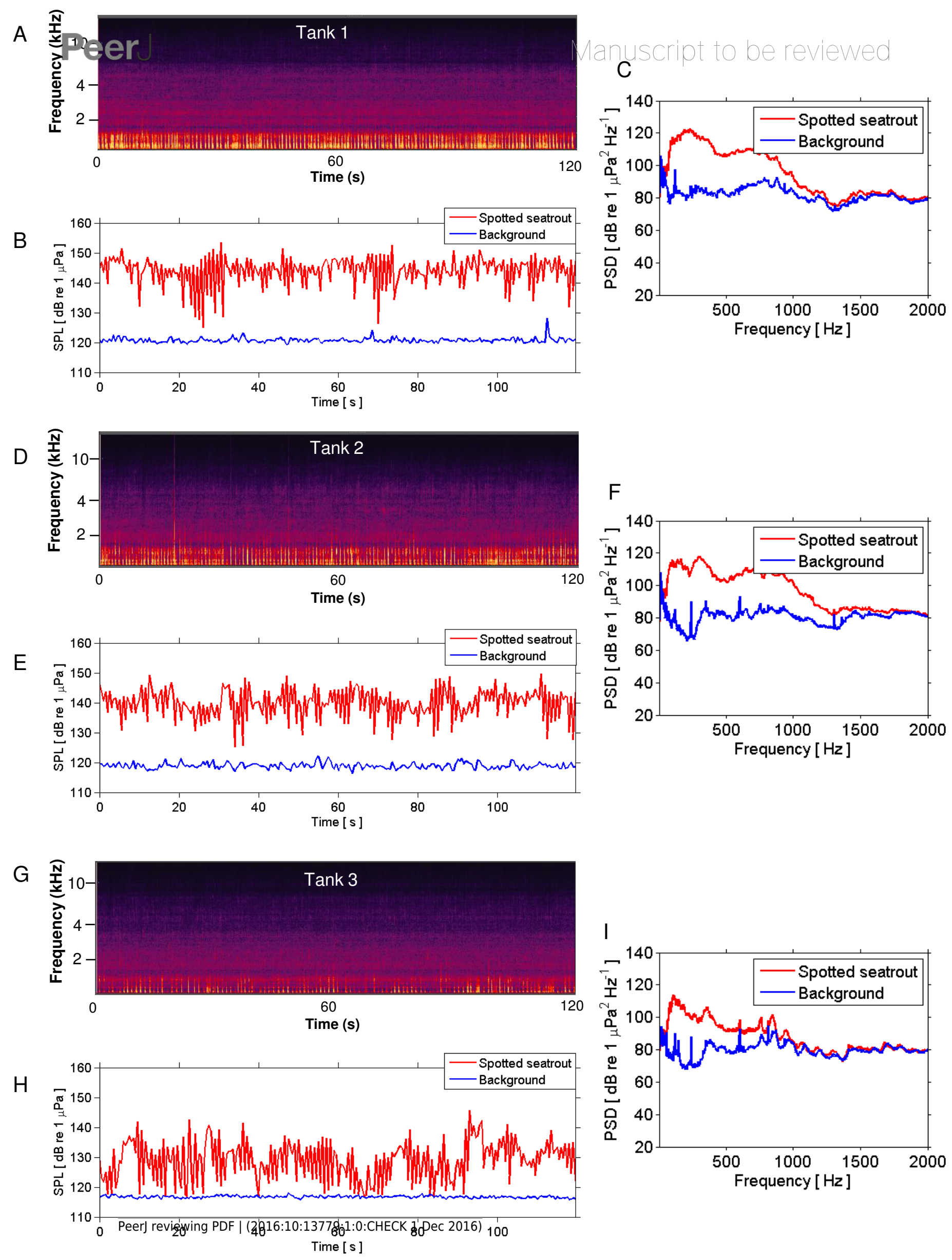


\section{Figure 4 (on next page)}

Sound production of spotted seatrout throughout study period.

Figure 4. Sound production by wild caught spotted seatrout (Cynoscion nebulosus) held in captivity throughout the entire study period. The number of drums, grunts, and staccatos in each 2 min 'wav file' was manually counted by an observer and plotted versus date with corresponding water temperatures for (A) Tank 1, (B) Tank 2, and (C) Tank 3. The numbers above the horizontal arrows indicate the number of hours of light present in the respective photoperiod. Boxes indicate rapid fluctuations in water temperature. Generally, abrupt rises in temperature were followed by an increase in calling, while abrupt drops were followed by a decrease in the amount of calling. 

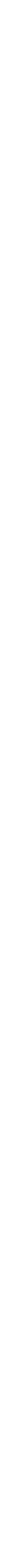
Figure $\mathbf{5}$ (on next page)

Daily patterns of sound production.

Figure 5. Daily patterns of sound production by spotted seatrout (Cynoscion nebulosus) in (A) Tank 1; (B) Tank 2; and (C) Tank 3. To examine these patterns, we determined the mean number of drums for each time interval (e.g., 12:00 to $12: 02 ; 12: 20$ to $12: 22 ; 12: 40$ to $12: 42$, 13:00 to $13: 02$, etc.) during the $14.5 \mathrm{~h}$ light photoperiod. The grey box indicates the time span of darkness during the $14.5 \mathrm{~h}$ light photoperiod. Standard deviations are reported as vertical bars. 
Peer J

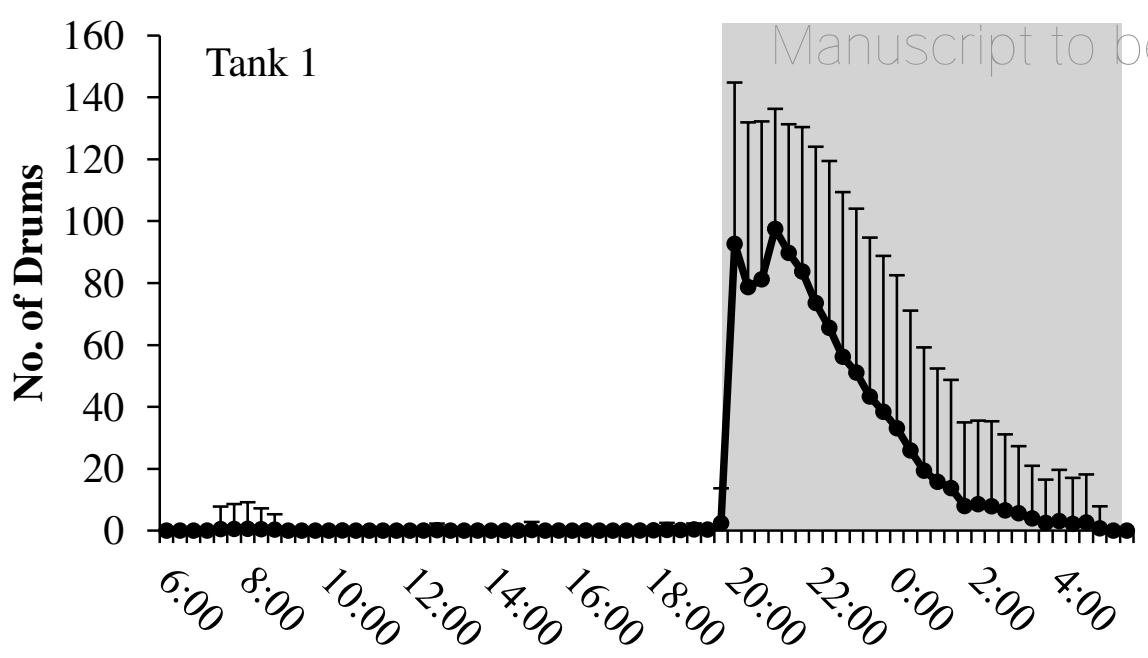

Time

B

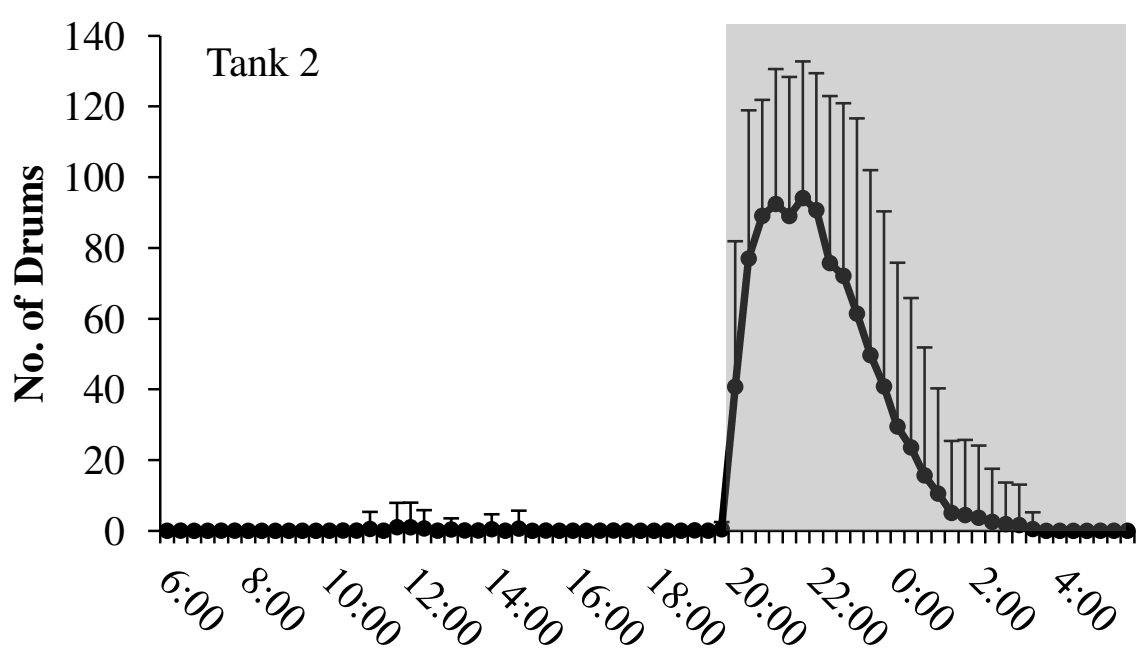

Time

C

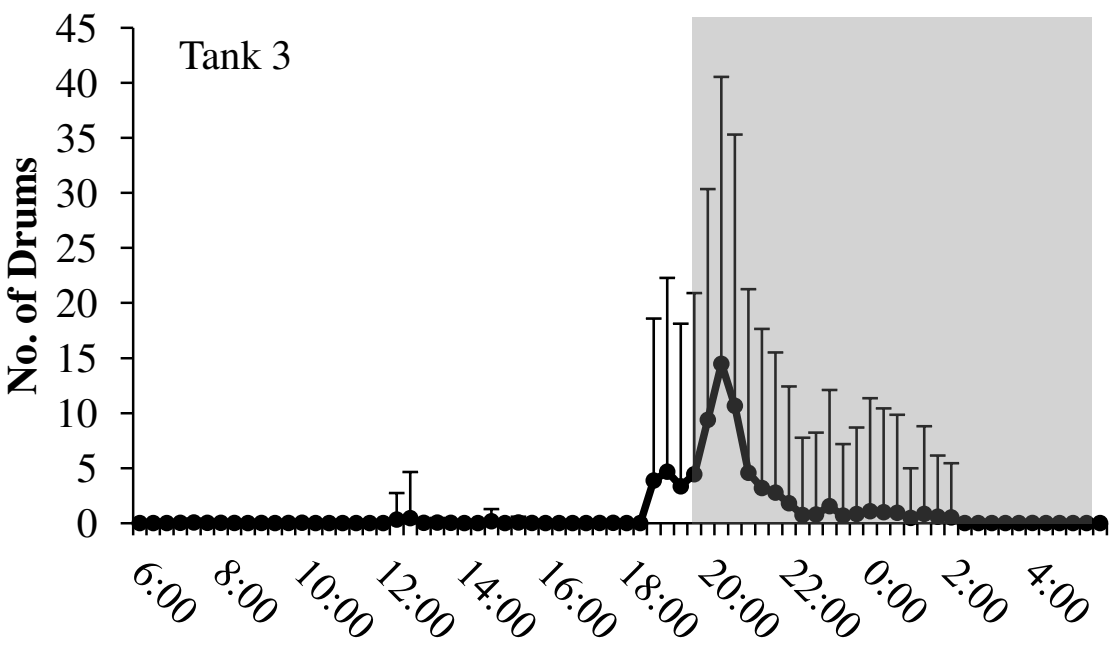

Time

Peer) reviewing PDF | (2016:10:13779:1:0:CHECK 1 Dec 2016) 
Figure 6 (on next page)

Sound production and spawning

Figure 6. Sound production and spawning of wild caught spotted seatrout (Cynoscion nebulosus) held in captivity throughout the entire study period. Calls per day and the number of eggs collected (i.e., the next morning) were plotted versus the date for (A) Tank 1, (B) Tank 2, and (C) Tank 3. 
Figure 7 (on next page)

Autocorrelation analysis

Figure 7. Autocorrelation analysis was used to determine the correlation between calling variables (i.e., number of calls and sound pressure level or SPL) and eggs collected at -5 to +5 day lags in wild caught spotted seatrout (Cynoscion nebulosus) held in captivity. (A) Tank 1 - number of calls, (B) Tank 1 - SPL, (C) Tank 2 - number of calls, (D) Tank 2 - SPL, (E) Tank 3 - number of calls, (F) Tank 3 - SPL. The dotted lines represent the $95 \%$ confidence interval. 


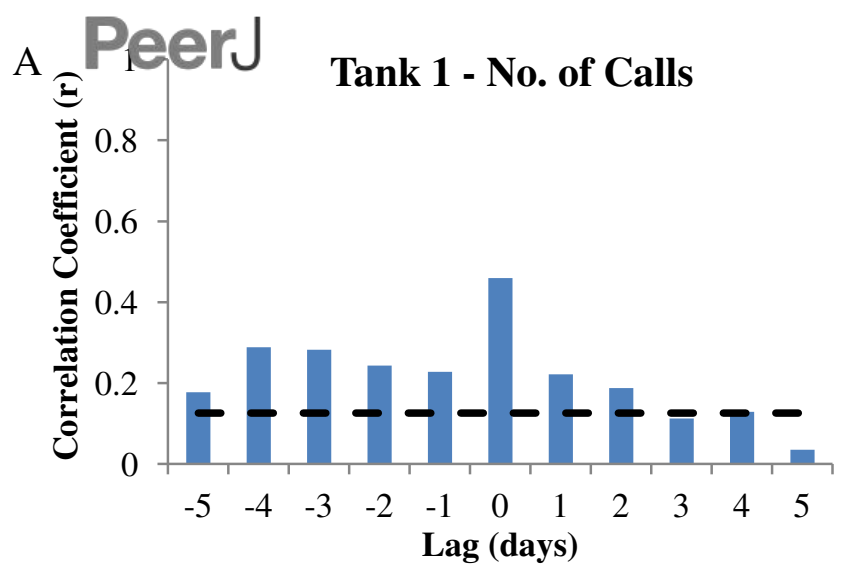

B
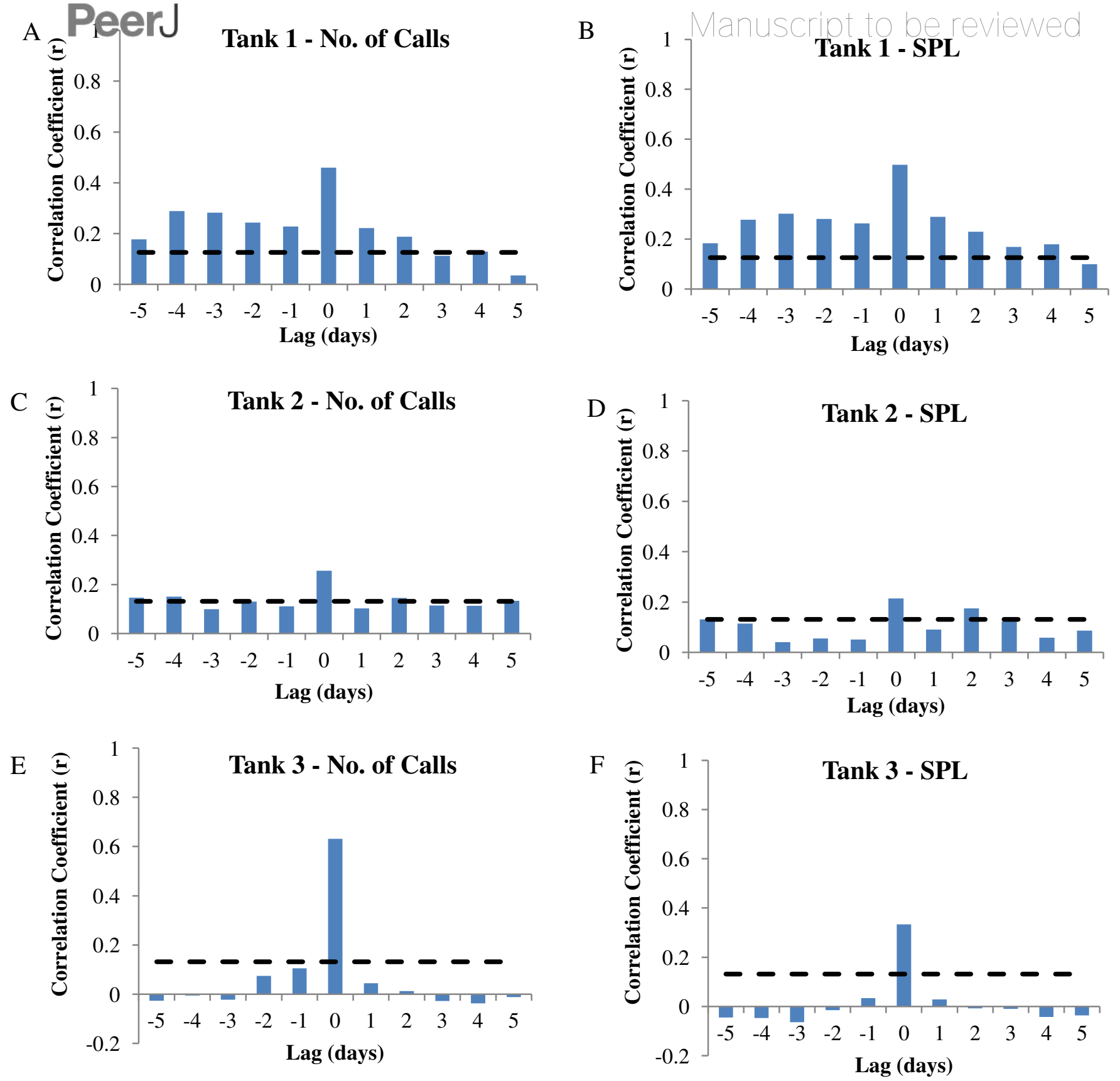


\section{Figure 8 (on next page)}

Comparison between spawning $\&$ non-spawning

Figure 8. A comparison of sound production of wild caught spotted seatrout (Cynoscion nebulosus) held in captivity for non-spawning and spawning periods. For each tank, $(A)$ the number of drums; (B) the number of grunts; $(C)$ the number of staccatos; and $(D)$ the sound pressure level (SPL) were compared for non-spawning and spawning nights. No spawn = blue bar; spawn = red bar. Standard errors are reported. 
PeerJ

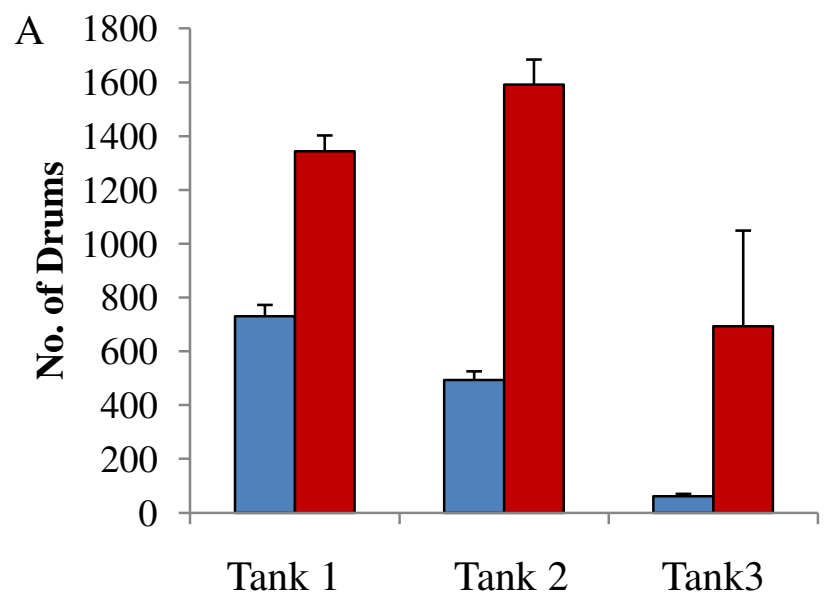

๑ No spawn $\square$ Spawn

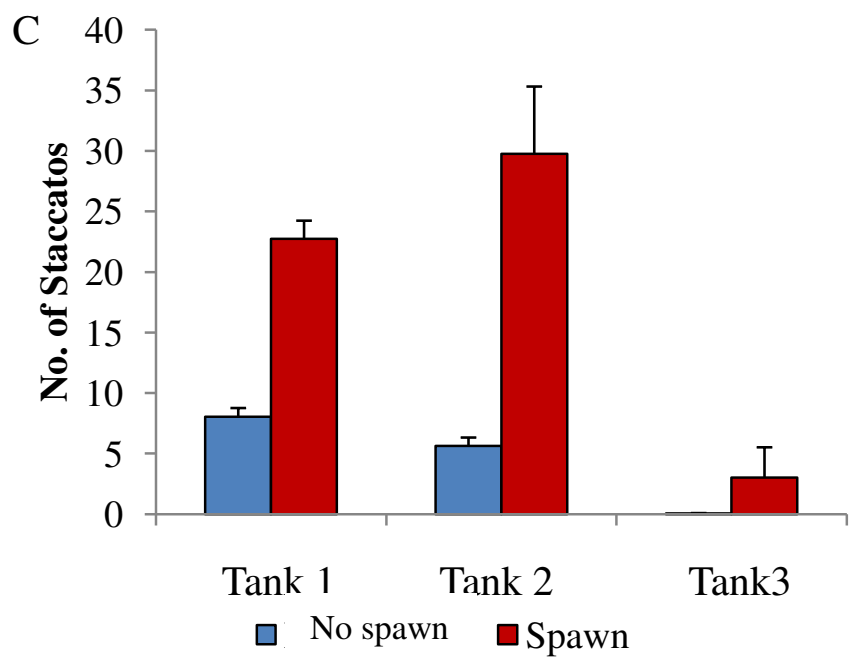

\section{Manuscript to be reviewed}

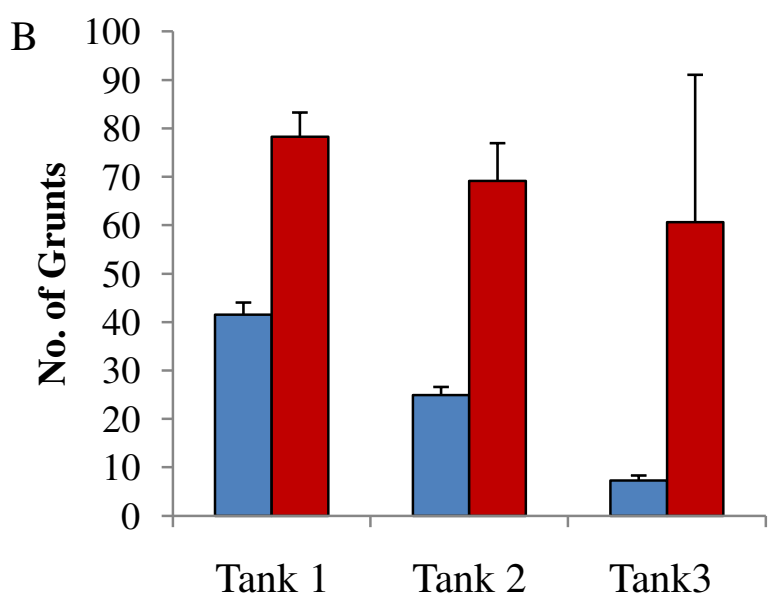

․ No spawn $\square$ Spawn

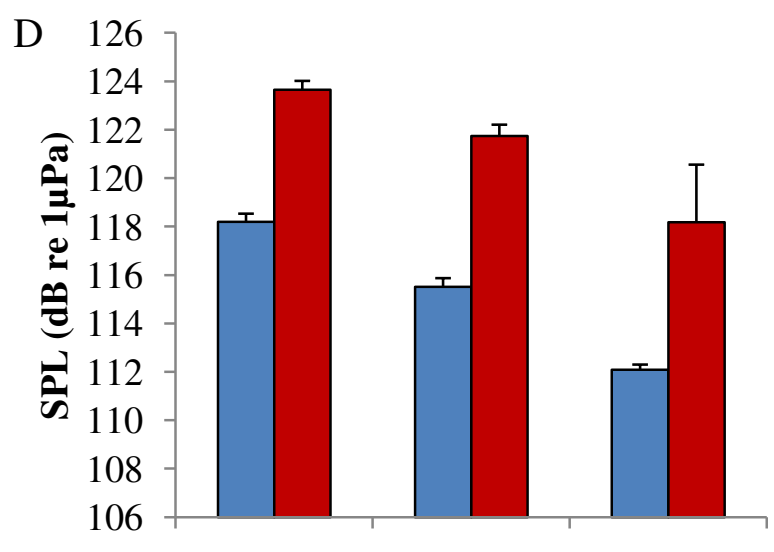

Tank 1 Tank 2 Tank3

๑ No spawn $\square$ Spawn 


\section{Figure 9 (on next page)}

Tank comparisons of sound production and spawning

Figure 9. Tank comparisons of sound production and spawning for wild caught spotted seatrout (Cynoscion nebulosus) held in captivity. The total number of eggs collected per gram of female biomass versus (A) the total number of calls per days monitored and (B) the mean received sound pressure level (SPL) for Tank 1, Tank 2, and Tank 3. The total number of calls per days monitored was calculated by summing the total number of drums, grunts, and staccatos from 18:00 to 06:00 throughout the entire study period and then dividing this value by the number of days monitored. The mean SPL for each tank was determined by averaging all the 2 min SPLS from 18:00 to 06:00 over the entire study period. 

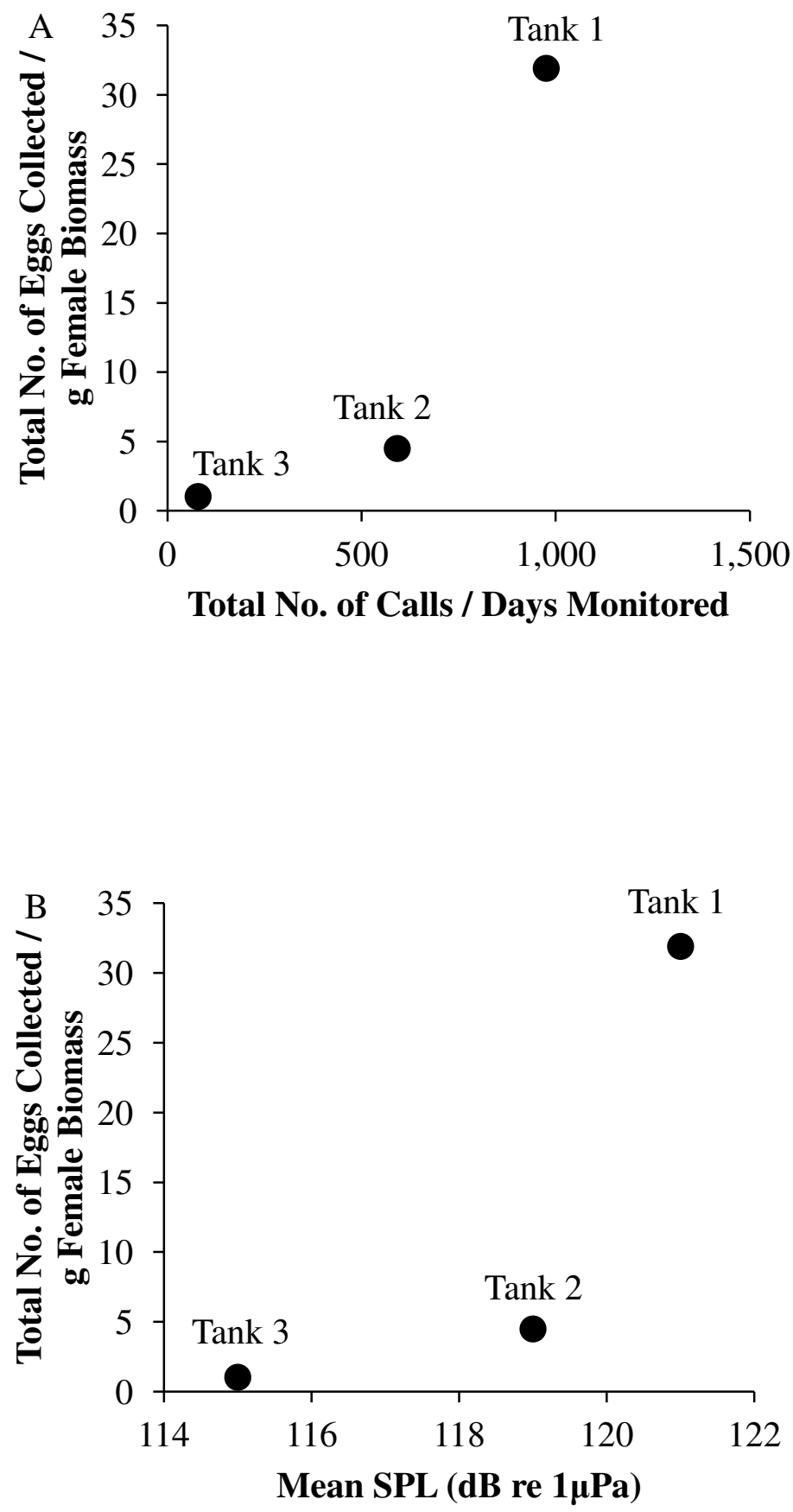